Board of Governors of the Federal Reserve System

International Finance Discussion Papers

Number 996

March 2010

Interest on Excess Reserves as a Monetary Policy Instrument:

The Experience of Foreign Central Banks

David Bowman, Etienne Gagnon, and Mike Leahy

NOTE: International International Finance Discussion Papers are preliminary materials circulated to stimulate discussion and critical comment. References to International Finance Discussion Papers (other than an acknowledgment that the writer has had access to unpublished material) should be cleared with the author or authors. Recent IFDPs are available on the Web at www.federalreserve.gov/pubs/ifdp/. This paper can be downloaded without charge from Social Science Research Network electronic library at www.ssrn.com. 


\title{
Interest on Excess Reserves as a Monetary Policy Instrument: The Experience of Foreign Central Banks
}

\author{
David Bowman, Etienne Gagnon, and Mike Leahy*
}

\begin{abstract}
:
This paper reviews the experience of eight major foreign central banks with policy interest rates comparable to the interest rate on excess reserves paid by the Federal Reserve. We pursue two main lines of inquiry: 1) To what extent have these policy interest rates been lower bounds for short-term market rates, and 2) to what extent has tightening that included increasing these policy rates been achieved without reliance on reductions in reserves or other deposits held at the central bank? The foreign experience suggests that policy rate floors can be effective lower bounds for market rates, although incomplete access to central bank accounts and interest on them weakens this result. In addition, the foreign experience suggests that tightening by increasing the interest rate paid on central bank balances can help reduce or eliminate the need to drain balances. These results are consistent with theoretical results that show that tightening without draining is possible, irrespective of whether excess reserves are large or small.
\end{abstract}

Keywords: excess reserves, policy interest rate, deposit facility, settlement balances, interest rate corridor, open market operations, fine-tuning operations, floor system, liquidity, quantitative easing, central bank balance sheet.

JEL classifications: E41, E43, E51,E52,E58

\footnotetext{
* The authors are staff economists in the Division of International Finance, Board of Governors of the Federal Reserve System, Washington, D.C. 20551 U.S.A. This note was prepared with assistance from Kelsey Ayres, Michiel De Pooter, Benjamin Hopkins, and Margaret Walton. We have benefited from helpful discussions with Brian Doyle, Steven Kamin, Patrice Robitaille, Nathan Sheets, Charles Thomas, and Beth Anne Wilson (Division of International Finance), Seth Carpenter, James Clouse, and Steve Meyer (Division of Monetary Affairs) and Spence Hilton (Federal Reserve Bank of New York), as well as from central bank colleagues at the Reserve Bank of Australia, the Bank of Canada, the Bank of England, the European Central Bank, the Bank of Japan, the Reserve Bank of New Zealand, Norges Bank, and Sveriges Riksbank. The views in in this paper are solely the responsibility of the authors and should not be interpreted as reflecting the views of the Board of Governors of the Federal Reserve System or of any other person associated with the Federal Reserve System.
} 
In October 2008, the Federal Reserve began paying interest on required and excess reserve balances. This note reviews the experience of eight major foreign central banks with policy interest rates comparable to the interest rate on excess reserves paid by the Federal Reserve. We pursue two main lines of inquiry: 1) To what extent have these policy interest rates been lower bounds for short-term market rates, and 2) to what extent has tightening that included increasing these policy rates been achieved without reliance on reductions in reserves or other deposits held at the central bank?

On the first question, we find that short-term market interest rates abroad have generally remained above the corresponding policy interest rates. Moreover, in cases in which central bank balances were abundant and a central bank's target for the overnight market rate was at or close to the policy rate meant to serve as a floor for the overnight rate, these policy rate floors appeared to contain downward movements in the market interest rates. A notable exception has occurred in the United Kingdom, where over the past year the sterling overnight market rate has generally traded below the policy rate floor. The U.K. experience is similar to that in the United States, where the federal funds rate has traded below the rate of interest paid on excess reserves. In both countries, the market for overnight funds includes lenders that do not earn interest on deposits at the central bank.

On the second question, we find multiple examples over the past ten years of policy tightenings by these central banks that were not accompanied by reductions in reserves or deposit balances. In each of these examples, the central bank increased the policy interest rate intended to serve as a floor for market rates, along with other policy rates, to guide market rates higher. To be sure, there were also examples in which policy tightening was accompanied by declines in balances, but in these instances the declines were small or related to special factors unrelated to the tightening, and it seems likely that larger declines in balances would have been necessary had the policy floor rate been left unchanged. On balance, we read the evidence as indicating that interest paid on excess reserve balances (or the equivalent) can be used by a central bank to tighten monetary policy and reduce reliance on supporting operations to drain balances.

The next two sections provide an overview of our findings on how well rates of interest paid on central bank balances have served as floors for short-term market rates and on the experiences of the central banks during episodes of tightening. Section 3 offers some brief concluding remarks. These sections are followed by two appendixes. The first presents the eight case studies that form the basis for the findings. The eight central banks covered are: the Reserve Bank of Australia, the Bank of Canada, the Bank of England, the European Central Bank, the Bank of Japan, the Reserve Bank of New Zealand, Norges Bank, and the Riksbank. Each case study reviews key features of the operational framework for monetary policy and the market for central bank balances and provides an assessment of (i) the extent to which the interest rate on excess reserves or deposits has been a floor for market rates and (ii) the extent to which aggregate balances have changed when monetary policy was adjusted. The second appendix offers a stylized graphical description of the way in which raising the rate of interest on reserves might lift market rates in corridor systems with adjustable rate floors. 


\section{Has the interest rate paid on central bank balances been a floor for market interest rates?}

Because deposit balances held at central banks are risk free and dominate all other investments in terms of liquidity, any institution that can hold balances at a central bank should be willing to lend those balances only if the interest rate earned in the market is at least as high as the rate the institution would receive from the central bank. This proposition forms the basis for the expectation that the interest rate paid on reserves should be a floor for market rates.

As we learned in the autumn of 2008, however, this expectation can fail if some institutions trading in the relevant money market do not have access to interest on deposits at the central bank. ${ }^{1}$ In such cases, the effectiveness of the central bank interest rate as a floor for short-term money market rates depends on the ability and willingness of institutions with access to borrow from institutions without access and on the competitive pressures to arbitrage any differences between the rates available at the central bank rate and in the market. To the extent that institutions with access demand at least some spread between borrowing and deposit rates to be willing to conduct the arbitrage, the difference between the rates may not go to zero. And if borrowers are good credit risks and few in number, they may have the market power to extract low borrowing rates from potential lenders with limited alternatives. Scarcity of borrowers might be reinforced during a crisis by widespread concerns about perceived creditworthiness and a resulting unwillingness to be seen in the market purchasing large volumes of overnight funds. ${ }^{2}$

Accordingly, unless all institutions that borrow and lend overnight funds are allowed to have deposits at the central bank and to earn interest on those deposits, there will be some scope for the overnight market rate to trade below the policy rate floor. Such scope may not be captured in measures of market rates that exclude important segments of the market, because they do not provide any indication of the rates the excluded institutions are receiving relative to the rate paid by the central bank. For example, the Reserve Bank of Australia, the European Central Bank (ECB), and the Bank of Japan operate on market rates that cover only institutions with access to the central banks' deposit facilities. In the cases of the ECB and the Bank of Japan, access is broad, so the market rates may well be indicative of overall market activity. The Bank of Canada, the Bank of England, and the Riksbank focus on market rates that apply both to institutions with access and to some without, and the Reserve Bank of New Zealand and Norges Bank monitor two overnight rates - one that covers only institutions with access and another that applies more broadly.

One simple test of the extent to which policy rate floors are effective in constraining declines in market rates is to examine the frequency with which market rates fall below policy rate floors. In general for the central banks considered, we do not observe failures of policy rate floors. Market rate spreads over policy rates are typically strictly positive, and in cases in which

\footnotetext{
${ }^{1}$ Exhibit $1 \mathrm{~b}$ shows the extent to which the effective federal funds rate has been below the interest rate on excess reserves by the Federal Reserve.

${ }^{2}$ It has been argued also that capital constraints might limit the arbitrage of spreads between the market rate and the interest rate paid on central bank balances, reducing the number of banks that might be in a position to borrow funds from institutions that do not have access to interest on holdings at the central bank. While such restraint might arise as a result of concerns over market discipline, the United States has been one of only a handful of countries that has included explicit leverage ratios in its regulatory framework.
} 
the spreads are negative, they are often negative by only small amounts or fail to remain negative for more than a day or so. (See exhibits $2 b$ through $9 b$.)

In some of these cases, however, this simple test may have less to say about the permeability of the policy rate floor than about the efficacy of open market operations. If central banks manage balances to keep market rates off the policy rate floor (for example, by targeting a rate in the center of the policy rate corridor), then the market rate spread over the policy rate is likely to be positive whether or not the policy rate floor would actually constrain the market rate. Such an interpretation would seem to apply generally to the results for the Reserve Bank of Australia, the Reserve Bank of New Zealand, and the Riksbank, because those central banks have managed market rates throughout our sample period to keep them strictly above policy rate floors.

In other cases, policy rate floors do appear to have been tested, in particular during the recent financial crisis. Five of the eight central banks we consider are currently operating what might be described as a "floor system," in which the banking system is left with substantial excess holdings of central bank balances and the short-term market rate is allowed to trade at a level close to the policy rate floor. These five are the ECB, the Bank of Japan, the Bank of England, the Bank of Canada, and Norges Bank. Of the five, the ECB and the Bank of Japan monitor a market rate corresponding entirely to participants with access to interest on central bank balances, which suggests in principle that the policy rate floors of these central banks should provide an effective lower bound for market lending rates under consideration.

- As shown in exhibits $2 \mathrm{a}$ and $2 \mathrm{~b}$, spreads between the market rate and the policy floor rate have stayed consistently positive for the ECB during this period, when central bank balances rose dramatically and became more volatile.

- Spreads for the Bank of Japan (exhibits 3a and 3b) are only from November 2008, when the Bank instituted a temporary facility to pay interest (10 basis points) on holdings in excess of required reserves. Since December 2008, when the Bank of Japan cut its target for the call rate to equal the interest rate it pays on excess reserves, the call rate has occasionally edged below the policy rate floor, but the size of such lapses has never been more than 2 basis points.

The Bank of England, the Bank of Canada, and Norges Bank monitor or target measures of market rates that include lending rates for institutions without access to interest on deposits at the central bank, so by those metrics, failures of policy rate floors are potentially more likely.

- The experience of the Bank of England illustrates this possibility. At times during the crisis, the sterling overnight interest rate has traded significantly below the interest rate paid by the Bank (exhibits $4 \mathrm{a}$ and $4 \mathrm{~b}$ ).

o Between September 2008 and March 2009, the unsecured sterling overnight rate frequently traded below the rate of interest paid by the Bank of England (BoE) in its deposit facility, at one point by as much as 36 basis points. The BoE was actively injecting liquidity during this tumultuous period and had narrowed its operating corridor in October 2008. Under these conditions, the deposit rate floor failed to constrain the sterling overnight rate. The fact that some lenders in the sterling market, 
such as small banks, local authorities, and some corporations, did not have accounts at the Bank, either because they were ineligible or because they had not applied, may have been a contributing factor to this failure.

o In March 2009, the BoE removed the limits on holdings that could be remunerated at its main policy rate (the Bank Rate), an action that made this rate the presumptive floor. Since that time, the market rate has generally traded below the main policy rate of $1 / 2$ percent, consistent with some continued albeit more limited permeability in the policy rate floor. ${ }^{3}$

- Spreads for the Bank of Canada (exhibits 5a and 5b) have recently edged below the deposit rate, but the magnitude of the breach has not been more than 2 basis points.

- Norges Bank is unique in our study in that it has maintained a "floor system" over the past ten years, not just during the crisis. As shown in exhibits $6 \mathrm{a}$ and $6 \mathrm{~b}$, the policy floor rate has been reliably effective in providing a lower bound for the short-term interbank rate published by the central bank. According to Norges Bank staff, however, occasional lapses in the policy rate floor do occur, and other measures of the cost of funding in Norwegian kroner, which include transactions by foreign banks without access to the central bank's deposit facility, indicate that trading has occurred on occasion at rates below the policy rate floor.

While incomplete access to central bank deposit facilities may weaken the effectiveness of the policy floor rate in constraining market rates, incomplete access need not limit significantly the effectiveness of a policy floor rate as a monetary policy tool. Even a porous floor rate can influence market rates if arbitrage keeps the spread between the policy rate and the market rate relatively stable when policy rates change. Our case studies do not provide examples of tightening when the spread is inverted, but they do support the finding that the positive spreads that prevailed during tightening episodes generally remained stable (that is, market rates typically rose in step with increases in the interest rate paid on excess reserves or its equivalent).

\section{Foreign central bank experience with policy tightening}

In this section, we summarize how aggregate balances of financial institutions at central banks have been adjusted during episodes of monetary policy tightening over the period since 1999. Each of the foreign central banks considered raised policy rates at least once over this period.

In most cases when these central banks tightened, they increased rates of interest paid on balances held at the central bank, and notably, such tightening was not accompanied by decreases in aggregate balances. ${ }^{4}$ The relevant episodes include one case of tightening by the Bank of Canada (exhibit 5a), three by Norges Bank (exhibit 6a), three by the Reserve Bank of Australia (exhibit 7a), four by the Reserve Bank of New Zealand (exhibit 8a), and one or two by the Riksbank (exhibit 9a). ${ }^{5}$ They include also two episodes of tightening by the ECB. The

\footnotetext{
${ }^{3}$ The market rate has averaged about 7 basis points below the policy rate, and it dipped 35 basis points below at one point.

${ }^{4}$ Tightening episodes are shaded in blue in exhibits 1a through 9a.

${ }^{5}$ During the first episode of tightening by the Riksbank in 2002, average balances actually rose slightly. During the second episode of tightening by the Riksbank in 2006-08, average balances fluctuated within a fairly tight range and
} 
ECB's case most resembles the Federal Reserve's in terms of the size of the economy served and the number of financial institutions. In addition, the ECB and the Federal Reserve both impose (lagged) reserve requirements on depository institutions. As shown in exhibit 2a, the ECB has accommodated an upward trend in reserves over the past decade, as required reserves have grown with deposits and economic activity, but there are no obvious periods of sustained subtrend growth in reserves during periods of ECB tightening.

These examples provide evidence that a central bank may successfully tighten monetary policy without draining reserve balances (or their equivalent) if it can increase the rate of interest paid on those balances. However, the examples do not guarantee that that capacity is available in all circumstances. A key question is whether raising the rate of interest paid on central bank balances would be just as effective in boosting market rates when balances are extraordinarily large. In models of market interest rate determination such as the one described in appendix 2, the scale of balances outstanding need not damp the effectiveness of tightening using the interest rate on reserves as a policy tool. Our case studies, however, do not provide many examples of such tightening when central bank balances were substantially in excess. In the three cases we have in which central banks with large outstanding balances tightened, two reduced the balances significantly before raising policy rates.

- Because the Bank of Japan had not begun to pay interest on excess reserves until November 2008, the successful winding down in 2006 of its quantitative easing policy was achieved without raising the interest rate paid on excess reserves. Accordingly, the policy tightening that occurred in 2006 was preceded by a large decline in aggregate balances held at the Bank of Japan. (See exhibit 3a.) ${ }^{6}$

- The Reserve Bank of Australia (exhibit 7a) has recently begun to tighten, raising the policy rate target three times since early October a total of 75 basis points. However, by the time of its first rate increase, the Reserve Bank had already drained the entire runup in balances that occurred in the second half of $2008{ }^{7}$

- The experience of Norway may be the most relevant to the question we are considering. As mentioned above, Norges Bank (exhibit 6a) routinely supplies excess funds to the market, to keep the market rate near the floor of its corridor, rather than in the center as many other central banks with corridor systems do.

o Norges Bank was able to guide the overnight market rate higher over an extended period between 2005 and 2008 without reducing aggregate liquidity supplied to the banking system, even as it kept the market sufficiently supplied with liquidity to keep the market rate near the floor of the corridor.

showed no real trend either upward or downward. In general, prior to the recent financial crisis, balances at the Riksbanks were quite small and on many days there were no balances held at the central bank either before or during this period of tightening, so that overall there seems to have been little or no link between balances and the level of the policy rate.

${ }^{6}$ Similarly, as shown in exhibit 1a, the Federal Reserve has tightened in two episodes since 1998, and both have been accompanied by reductions in the deposits of depository institutions. These episodes occurred before the Federal Reserve had the authority to pay interest on reserves.

${ }^{7}$ Nonetheless, during the period of tightening, settlement balances rose substantially, consistent with the view that at least some of the draining of reserves that occurred before the tightening may not have been needed to support the policy rate. 
o Norges Bank has also implemented two rate increases as it began to exit from the policy accommodation provided during the crisis. These increases came after the central bank let liquidity run off some in the second half of last year, but liquidity has not fallen to pre-crisis levels. In fact, during the fourth quarter, when the Norges Bank raised its policy rate a cumulative 50 basis points, liquidity balances rose sharply, consistent with the continued operation of a floor system in which the stock of liquidity is not tightly managed as long as it remains in surplus.

It should be noted that there were also some episodes of tightening in which aggregate balances declined. ${ }^{8}$ These examples suggest that raising the rate of interest paid on central bank balances does not necessarily eliminate the need to reduce aggregate balances to hit the central bank's target rate, and central banks with corridor systems may find that at times they must drain aggregate balances to support policy tightening. However, given that the declines in balances in these examples were generally small, it seems plausible that raising the floor rate reduced the need for larger reductions in aggregate balances.

\section{Concluding remarks}

The foreign experience with paying interest on central bank balances suggests that policy rate floors can be effective lower bounds for market rates and that tightening by raising the interest rate paid on central bank balances can help reduce or eliminate the need to drain balances to bring about higher market rates. In addition, the experience of Norges Bank supports the view that raising the interest rate paid on reserves can effect a tightening of monetary policy even when reserves outstanding are substantially in excess - a situation that several central banks confront at present. Our findings on the experience with monetary policy tightening are also consistent with the theory described in appendix 2, which shows that tightening without draining is possible, irrespective of whether excess reserves are large or small.

These conclusions are drawn from observation of the experiences of eight central banks over the past decade or so. However, it is important to note that the foreign experience was not uniform across central banks and across tightening episodes. We saw that in some circumstances the central bank's policy rate failed to provide an impermeable floor for short-term market rates, particularly in cases in which money-market participants had incomplete access to interest earnings on deposits at the central bank. In addition, we noted that in some circumstances holdings of balances at the central bank did decline during periods of central bank tightening, even when the central bank raised the interest rate paid on excess reserves, although in most cases these declines seemed either small or to have been augmented by other factors unrelated to the policy tightening.

\footnotetext{
${ }^{8}$ There were two episodes of tightening by the Bank of England (exhibit 4a) when it also raised the interest rate paid on deposits, and during these periods balances declined somewhat. The Bank of Canada (exhibit 5a) tightened in sequences of steps four times over the period, and settlement balances fell in three of the episodes, but those declines appear to be small, temporary, or related to special factors discussed in the case study for the Bank of Canada. The Reserve Bank of Australia (exhibit 7a) tightened from late 1999 to early 2000, and during this period balances declined, although the scale of the decline was small.
} 
Given the variety of outcomes observed, consideration of multiple monetary policy instruments to exit from the current environment of low interest rates and abundant liquidity would seem to be prudent. However, our results indicate that the interest rate paid on excess reserves should be an important component of the complement of instruments to consider. 


\section{Appendix 1: Case Studies}

In this appendix we present the case studies for the eight central banks. For each, we review the policy implementation framework with a focus on the remuneration of balances held at the central bank. In addition, we summarize key features of the short-term interbank funding markets that the central banks attempt to influence, the covariation between monetary policy adjustments and central bank balances, and the extent to which the rate the central bank pays on balances has served as a floor for the short-term market interest rate monitored or targeted by the central bank.

The order in which the case studies are discussed is shown in the table of contents below. The first central banks considered are those currently operating what might be described as a "floor system." These are the ECB, the Bank of Japan, the Bank of England, the Bank of Canada, and Norges Bank. The remaining central banks - the Reserve Bank of Australia, the Reserve Bank of New Zealand, and the Riksbank - appear to be operating more conventional corridor systems in which short-term market rates are kept nearer the center of the policy rate corridor.

\section{Appendix 1 Contents}

European Central Bank

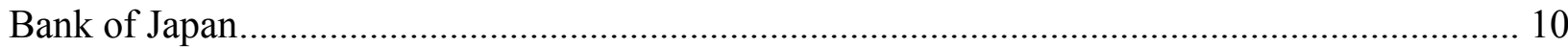

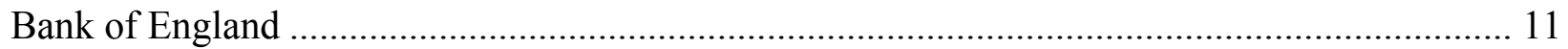

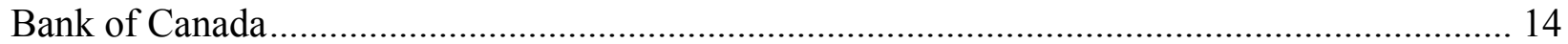

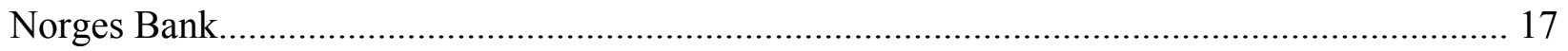

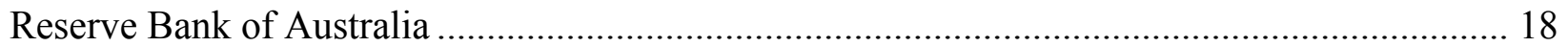

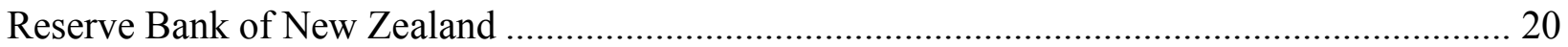

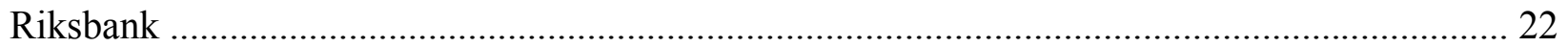

\section{European Central Bank}

The European Central Bank (ECB) guides short-term market rates with a variety of open market operations and with its standing overnight deposit and lending facilities (exhibit 2a). Its benchmark policy rate is the minimum bid rate it sets in its main refinancing operations. In these operations, the ECB conducts weekly auctions against collateral of funds with a one-week maturity. The auction determines the main refinancing rate (MRR). ${ }^{9}$

Credit institutions are required to hold minimum reserves in current accounts at the various national central banks of the countries where their branches are located. Required reserve holdings are remunerated at the average MRR over the maintenance period, but reserve holdings above the required reserves are not remunerated. Euro-area banks therefore have an

\footnotetext{
${ }^{9}$ The MRR can differ from the minimum bid rate at the main refinancing operations when the ECB holds variable rate tenders and the lowest successful rate at the auction comes in above the minimum bid rate.
} 
incentive to fulfill their reserve requirements exactly and to place any excess funds in the ECB's deposit facility. The amounts deposited in the deposit facility do not count towards satisfying banks' reserve requirement, nor are excess reserves automatically transferred to the deposit facility. For most institutions, the minimum reserve requirements are based on end-of-month balance sheet data referring to the calendar month two months before the start of the applicable maintenance period. Compliance with the reserve requirement is determined on the basis of the institutions' average daily reserve holdings over the maintenance period, and non-compliance with the minimum reserve obligations is subject to a sizeable penalty.

Before the current crisis, banks generally made very limited use the ECB's standing marginal lending and borrowing facilities, as their rates were normally punitive compared with the rates available in interbank markets. Prior to October 2008, the lending and the deposit rates in these facilities were set at \pm 100 basis points around the minimum bid rate for the main refinancing operations. However, on October 9, 2008, the ECB narrowed the width of the corridor to \pm 50 basis points around the benchmark policy rate to help to limit the variation in market interest rates as large liquidity injections were conducted. After market conditions normalized somewhat in early 2009 , the ECB widened the corridor back to \pm 100 basis points, but once again narrowed the corridor, to \pm 75 basis points, when it cut its benchmark policy rate to 1 percent in May 2009.

\section{EONIA}

The ECB's chief indicator of overnight interest rates in the euro area, shown in the upper panel of exhibit 2a, is the "euro overnight index average" rate, known as the EONIA rate, an effective overnight rate computed as a weighted average of all overnight unsecured lending transactions in the interbank market initiated by a panel of around 50 contributing banks active in the euro area. Although the panel includes some branches of foreign banks, all members of the panel are subject to the ECB's reserve requirements and, given their size and scope of operations, would normally have access to both the ECB's refinancing operations and standing facilities. $^{10}$

\section{Balances at the ECB during periods of tightening}

As shown in the lower panel of exhibit 2a, deposits at the ECB (the sum of current account deposits and the amounts held in the marginal deposit facility) show a smooth, gradual upward drift over 1999-2007, regardless of whether the ECB was tightening or easing, and show little evidence of negative relationship with the overnight rate at medium-term frequencies. In fact, the trend rate of growth was slightly lower over the period of easing from 2001 to 2003 than during the two tightening episodes (1999-2000 and 2005-07).

\footnotetext{
${ }^{10}$ Of the approximately 6,500 financial institutions subject to minimum reserve requirements in the euro area, roughly 2,800 have access to the deposit facility and 2,100 are eligible to participate in refinancing operations. The number of institutions able to participate in fine-tuning operations, which had been much smaller prior to the crisis (fewer than 200), was widened during the crisis to include all institutions eligible to participate in refinancing operations.
} 


\section{Balances at the ECB during the crisis}

Deposits at the ECB became much more volatile during the financial crisis. The amount held in the ECB's marginal deposit facility skyrocketed as the ECB conducted liquidity injections more frequently and for a wider range of maturities. Balances subsequently declined at the beginning of 2009, as maturing amounts from earlier short-term refinancing operations were allowed to run off without replacement. Deposits jumped again in June and December in response to the the large injections of liquidity via the one-year refinancing operations conducted in those months.

\section{Spread between the EONIA rate and the deposit rate}

Prior to the crisis, the ECB managed liquidity to steer the EONIA rate to be close to the center of its policy corridor. It was largely successful, as seen in exhibit $2 b$, although rates were sometimes volatile at the end of maintenance periods. ${ }^{11}$

In the fall of 2008, as a result of the expansion in liquidity provided by the ECB, the overnight interbank borrowing rate moved close to the floor of the ECB's corridor (exhibit 2b). However, the EONIA rate has not fallen below the deposit rate during the financial crisis, even when excess liquidity and use of the deposit facility were very high. Accordingly, the spread between the EONIA and deposit rates has remained positive.

\section{Bank of Japan}

The Bank of Japan (exhibits 3a and 3b) has long had a Complementary Lending Facility, which offers loans at a rate that is normally 25 basis points above the target for the uncollateralized overnight call rate, but the Bank had no standing deposit facility until 2008. Accordingly, the Bank of Japan implemented monetary policy chiefly through open market operations.

In November 2008, the Bank of Japan instituted its Complementary Deposit Facility as a temporary measure at the same time that the Bank reduced its target for the uncollateralized overnight call rate to 30 basis points. The rate of interest paid at the deposit facility was set at 10 basis points. When the Bank lowered its target for the call rate to 10 basis points at its December 19 policy meeting, the rate paid at the deposit facility was left at 10 basis points, so that the target for the call rate effectively became the floor of the corridor as well. ${ }^{12}$ When the Complementary Deposit Facility was first introduced, it was to end on March 16, 2009. At subsequent policy meetings in 2009, the Bank postponed the termination of the Facility, and currently the expiration date has been left indefinite.

The deposit facility is a means by which the Bank can pay interest on excess reserve balances. All financial institutions either subject to reserve requirements or with a current

\footnotetext{
${ }^{11}$ In March 2004, the timing of the reserve maintenance periods was adjusted to start on the day of the settlement of the main refinancing operation immediately following the ECB's Governing Council interest rate meetings. Prior to this, expectations of a change in the policy rate could sometimes affect bidding behavior in the overnight market and cause divergences between EONIA and the center of the ECB's policy rate corridor.

${ }^{12}$ At its December policy meeting the Bank of Japan also lowered the spread between the loan rate and its target for the uncollateralized overnight call rate to 20 basis points.
} 
account at the Bank of Japan are eligible to earn interest through the facility. The interest each institution receives for a reserve maintenance period is based on its current account balances in excess of required reserves; no interest is paid on required reserves.

\section{Call rate}

The uncollateralized overnight call rate is similar to the federal funds rate, in that it is a daily weighted average of transactions in the uncollateralized overnight market. Participants in the market include domestic city, regional, and trust banks, foreign banks, securities companies, and other firms dealing in Japanese money markets. All of the economically important participants active in the call market are also eligible to participate in the deposit facility.

\section{Balances during periods of tightening}

Over most of this decade, the Bank of Japan conducted a policy of quantitative easing, which began in 2001 and ended in 2006 . Under this policy, the Bank raised its target for the current account to far above what would be necessary to keep the overnight call rate near zero. As can be seen in lower panel of exhibit $3 \mathrm{a}$, there is a clear negative relation between the current account and the Bank of Japan's target rate at the end of the period of quantitative easing, as the Bank first allowed current accounts to decline before moving to raise rates.

\section{Balances during the crisis}

Current account balances held at the Bank of Japan have risen since the institution of the deposit facility but remain well below their levels under quantitative easing.

\section{Spread between call rate and the deposit rate}

Although the Bank of Japan did not have a deposit facility until 2008, under quantitative easing it effectively created a floor system, with the floor set at a zero interest rate. This was an obvious case in which the level of deposits at the central bank was effectively divorced from the target for the overnight rate, as the Bank purposefully injected far more liquidity than was necessary to keep rates near zero. The upper panel of exhibit $3 \mathrm{a}$ indicates that the zero lower bound successfully restrained the call rate.

As can be seen in exhibit $3 \mathrm{~b}$, the overnight call rate has occasionally fallen below the Bank of Japan's deposit rate in the period since November 2008, but never by more than 2 basis points. On the whole, therefore, the deposit facility seems to have provided an effective floor.

\section{Bank of England}

The Bank of England (BoE) made a significant change to its framework for monetary policy operations in May 2006. ${ }^{13}$ At that time, the BoE established the official Bank Rate as its benchmark policy rate and began paying the Bank Rate on reserves. The BoE also paid interest on non-reserve deposits, the equivalent of excess reserves, at a rate below the Bank Rate.

\footnotetext{
${ }^{13}$ The break between the left and right panels of exhibit 4a occurs between April and May of 2006.
} 
Until March 2009, the payment of interest on reserve balances at the BoE was based on a system of voluntary declarations by members of the Bank's reserves remuneration scheme. Participating institutions selected a target for the average balance of reserves held at the Bank over periods between the Monetary Policy Committee's monthly interest rate decisions. If a participant's average balance over this maintenance period fell within a range around the declared target, the balance was remunerated at the Bank Rate. Reserves in excess of the target range were not automatically remunerated and, if reserves fell short of the target range, a penalty was paid.

The range within which targeted reserves were remunerated changed several times following its introduction. (See the yellow shaded area of the lower right panel of exhibit 4a.) Initially set at 1 percent above and below an institution's target, the range was widened to 371/2 percent in September 2007 as the BoE sought to increase the aggregate supply of reserves without penalizing banks for having excess reserves. The range was modified seven more times before the BoE eliminated it entirely on March 5, 2009, as the Bank of England lowered its Bank Rate to $1 / 2$ percent, announced an asset purchase program financed by the issuance of reserves, and suspended the setting of individual reserves targets in favor of a system in which all reserves are remunerated at the Bank Rate.

Reserves held in excess of the target range can earn interest at a spread below the Bank Rate if they are placed in the BoE's deposit facility. This facility was introduced in June 2001 to complement an existing lending facility in the prevention of large movements in overnight rates. The interest rate received on deposits in the facility was initially set at 100 basis points below the official repo rate, which was the main policy rate at the time, whereas the rate charged in the lending facility was 100 basis points above the official repo rate. Since then, the rate paid on deposits has changed a number of times. On March 14, 2005, the \pm 100 -basis-point corridor was narrowed to \pm 25 basis points to stabilize the overnight rate ahead of the introduction of remunerated reserves. From May 2006 to October 2008, the overnight deposit facility paid a rate 100 basis points below the Bank Rate on all days except the last day of a maintenance period, when it paid a rate 25 basis points below the Bank Rate. ${ }^{14}$ In October 2008, along with a major restructuring of the Bank's standing facilities (now called "operational standing facilities"), ${ }^{15}$ the BoE raised the rate of interest paid in its deposit facility to 25 basis points below the official Bank Rate on all days of the maintenance period. Finally, on March 5, 2009, when the central bank started paying interest on all reserves as it brought the Bank Rate to $1 / 2$ percent, it also lowered the deposit rate to zero. With this change, the deposit rate became largely irrelevant for reserve-scheme participants. Because the BoE kept the lending rate at 25 basis points above the Bank Rate, however, the central bank now operates an asymmetric corridor in which the Bank Rate is closer to the lending rate than to the deposit rate.

\section{Sterling overnight interest rate}

The condition of money markets is typically gauged with reference to the sterling overnight interbank average (SONIA) rate, shown in the upper panel of exhibit 4a. The SONIA

\footnotetext{
${ }^{14}$ Documents discussing the deposit and lending facilities during this period seem to indicate that the BOE wished to construct them in such a way that would discourage their regular use. Indeed, the facilities were used a total of only 7 and 21 days, respectively, from May 2006 to August 2007.

${ }^{15}$ The chief motivation for the restructuring was to reduce stigma at the BoE's lending facility.
} 
rate is a weighted average of unsecured sterling overnight transaction rates. ${ }^{16}$ These transactions may involve participants that are not reserve account holders and/or deposit facility members, such as small banks, local authorities, and some corporations.

As seen in the upper-left panel of exhibit 4a, the introduction of the deposit facility in June 2001 helped prevent large downward movements in overnight rates and the volatility of the SONIA rate fell somewhat, although it remained high in comparison to the volatility of overnight rates in other economies. The narrowing of the corridor to 25 basis points in March 2005 contributed to a noticeable reduction in the volatility of the SONIA rate. The BoE's framework of operations in the sterling money market launched in May 2006 gave participating banks significantly more flexibility in the management of their liquidity which, the recent turmoil aside, contributed greatly to a sharp reduction in the volatility of the overnight interest rate.

\section{Balances at the central bank during periods of tightening}

There are three tightening episodes over our sample period: September 1999 to February 2000 ( +100 basis points), November 2003 to August 2004 (+125 basis points), and August 2006 to July 2007 ( +125 basis points). The first episode occurred prior to the introduction of interest on deposits at the Bank. The second shows no prominent movement in reserves over the period, with reserves ending the episode only slightly below their level at the beginning. In the most recent episode, central bank balances moved inversely with the Bank Rate, declining about $£ 2$ billion (about 10 percent).

\section{Balances in 2005 and 2006}

The narrowing of the corridor in March 2005, which reduced the cost of borrowing central bank funds and of holding deposits at the central bank, prompted a noticeable increase in the demand for balances, which the BoE accommodated, as seen in the lower-left panel of exhibit 4a. This increase was dwarfed, however, by the subsequent rise in reserves that accompanied the introduction of interest on holdings at the central bank. ${ }^{17}$ The latter increase in demand, which the BoE also accommodated, occurred without any change in the general level of the SONIA rate.

\section{Balances during the turmoil}

The aggregate level of balances has fluctuated substantially over the past year due to the influence of market uncertainty on demand and the introduction of quantitative easing measures. From early March 2009 until early August, the BoE's approach was to ensure that the net supply of reserves was close to the aggregate level of reserves targets set by reserves scheme participants for the maintenance period starting on March 5, plus the amount of reserves injected through its asset purchase program. In August, the BoE discontinued its weekly short-term open market operations, resulting in a $£ 30$ billion drop in reserve balances. Weekly repo rates had

\footnotetext{
${ }^{16}$ The transactions included in the average are those brokered in London by Wholesale Markets Brokers' Association members between midnight and 4:15 p.m., with a minimum deal size of $£ 25$ million (\$41 million equivalent).

${ }^{17}$ The prominence of this increase is masked in exhibit 4a by the different scales in the lower-left and lower-right panels.
} 
fallen below the Bank Rate by about 7-8 basis points, making it possible for institutions with access to the deposit facility to obtain funds from the central bank and then turn a profit by simply depositing them back.

During the fourth quarter of 2008, deposits in the BoE's deposit facility rose in response to the Bank's injections of liquidity, but since March 2009, when all reserves became eligible for remuneration at the Bank Rate, use of the deposit facility has dropped to zero.

\section{Spreads}

As shown in the top panel of exhibit 4b, for most of the period since June 2001, when the Bank of England first established its deposit facility, the deposit rate has served as a lower bound for the SONIA rate. Following the bankruptcy of Lehman Brothers, however, the Bank of England increased reserves sharply and the SONIA rate declined to as much as 36 basis points below the BoE's deposit rate. This leakage likely reflected a combination of factors whose respective contributions are difficult to assess. It is possible that some lenders in this market did not have accounts at the BoE, either because they were ineligible or had not applied. These lenders may have been more inclined to lend sterling at rates below the overnight deposit facility rate as the opportunity cost of lending excess funds was to earn no interest on them. There could also have been a composition effect at play such that the most creditworthy member institutions were more likely to receive loans from those institutions with surplus funds but without access to the BoE. Lenders may have been concerned about providing funds to other institutions and with less competition for the funds, these lenders may have been willing to accept a lower rate than they might have under more normal circumstances.

Since March 2009, when the remuneration at the Bank Rate was extended to all reserves and the deposit rate was lowered to zero, there have been no observations of the overnight rate below the deposit rate. Over that period, however, the Bank Rate might arguably have become the dominant policy floor rate. In fact, large deviations of the SONIA rate from the Bank Rate have not occurred over the period since March, and the SONIA rate has become markedly less volatile. (See lower panel of exhibit 4b.) The remuneration of all reserves may have improved the ability of reserve-scheme participants to arbitrage away differences between market rates and the Bank Rate. However, non-participation in the BoE's reserves remuneration scheme may still be preventing complete closure of the gap between the Bank Rate and the SONIA rate, which has traded on average about 7 basis points below the Bank Rate over this period, occasionally falling below the Bank Rate by as much as 35 basis points.

\section{Bank of Canada}

The Bank of Canada (BoC) implements monetary policy by setting a target for the overnight interest rate, within the limits of its operating band (i.e., the rates received and paid at its standing lending and deposit facilities). (See exhibit 5a.) When necessary, the BoC also conducts open market operations at the target rate to support its policy objectives. Because there is no reserve requirement, participants ordinarily seek to achieve zero balances by the end of the day; otherwise they must borrow from or lend to the $\mathrm{BoC}$ to set their intraday account balances to zero. Prior to the current crisis, banks could earn the target rate less 25 basis points on 
overnight deposits at the $\mathrm{BoC}$ and would pay the target rate plus 25 basis points on overnight loans (the Bank Rate). ${ }^{18}$

In response to pressures associated with the financial crisis, the $\mathrm{BoC}$ moved its target rate in April 2009 to $1 / 4$ percent, which it considers to be the "effective lower bound" for the overnight interest rate, and implemented an asymmetric corridor system, with the deposit rate equal to the target rate and the lending rate equal to $1 / 2$ percent.

\section{Overnight interbank market}

The Bank of Canada targets an overnight market rate for collateralized transactions. It uses two indicators as proxies for this rate. The first is the overnight money market financing rate (displayed in exhibit 5a), which is derived from an end-of-day survey of major participants in the collateralized overnight market. ${ }^{19}$ Some counterparties in this market, such as pension funds, do not have access to the Bank of Canada's deposit facility. The second indicator is the Canadian Overnight Repo Rate Average (or CORRA, not shown), for which coverage is limited to on-screen repo transactions. ${ }^{20}$

\section{Settlement balances}

Even though the Bank of Canada does not use settlement balances to implement or signal a change in its policy stance, which is done instead through the choice of a target for the overnight rate, the level of settlement balances may be altered to reinforce the target for the overnight rate if temporary pressures cause the overnight rate to deviate from target. Examples of such adjustments include those associated with the year-end turn of Y2K and liquidity needs following September 11, 2001.

At times the BoC has also changed the level of settlement balances for more extended periods. Closely following the introduction in February 1999 of the Large Value Transfer System (LVTS) - an electronic fund transfer system that settles large payments in Canadasettlement balances were set higher to help participants adjust to the new system and to reinforce trading at the mid-point of the band. More recently, before the financial crisis, the Bank had targeted a small positive level of settlement balances (C\$25 million) in order to alleviate transactions costs and other frictions from the end-of-day settlement process, thereby reducing the need for LVTS participants to take frequent, small advances from the Bank.

\section{Settlement balances during periods of tightening}

As shown in exhibit 5a, settlement balances show no clear pattern across episodes of monetary tightening. The $\mathrm{BoC}$ decreased net settlement balances as it increased its target a total of 125 basis points between November 1999 and May 2000. However, this decline likely captures the removal of settlement balances injected to accommodate demand ahead of the start of Y2K and to ease the transition to the new LVTS system. The tightening episode between April 2002 and April 2003, which was also 125 basis points, was accompanied by a marginal fall

\footnotetext{
${ }^{18}$ See Howard (2007) for a more detailed description of the implementation of monetary policy in Canada.

${ }^{19}$ Government of Canada securities account for nearly all of the collateral pledged.

${ }^{20}$ The uncollateralized interbank market accounts for a very small proportion of overnight lending activity.
} 
in the quantity of settlement balances. During the brief tightening episode in 2004, in which the target was increased 50 basis points, settlement balances were little changed or up very slightly on balance.

The tightening episode between September 2005 and May 2006 involved a notable but transient decline in reserves, as the BoC temporarily left banks short on balances, driving them to borrow at the Bank's lending facility, to prompt the overnight rate to move higher. Once the rate hikes ended, the BoC restored balances to a surplus position again with no downward movement in the overnight rate.

\section{Settlement balances during the crisis}

The BoC increased the quantity of settlement balances in mid-August 2007 in response to heightened financial uncertainty and concurrent upward pressure on the overnight rate. It then reverted to a more typical target for settlement balances (C\$25 million) in March 2008. On April 21, 2009, when the $\mathrm{BoC}$ lowered its target rate to $1 / 4$ percent at the lower limit of a 25 basis point corridor, (rather than the mid-point), it also provided C $\$ 3$ billion (US\$2.8 billion equivalent) in excess settlement balances to help guide the overnight to the floor of the corridor. Normally, the deposit facility is not used, since it is generally beneficial and operationally feasible to find counterparties in the market with a shortage willing to pay the target rate, but since the move to the floor system, the amount deposited daily at the standing facility has been close to C $\$ 3$ billion. In choosing its $\mathrm{C} \$ 3$ billion target, the $\mathrm{BoC}$ sought to make settlement balances sufficiently abundant to drive the overnight rate to the floor but not so large as to suggest that the Bank is implementing a policy of quantitative easing. In addition, it was thought that maintaining a clear target for excess reserves, rather than leaving the excess to fluctuate unmanaged above some threshold, would help limit uncertainty among banks.

\section{Spread between the overnight rate and the floor of the corridor}

As seen in the upper panel of exhibit 5a, the Bank of Canada has been very successful at keeping the overnight rate near its target, even throughout the financial crisis. Prior to April 2009, this success likely reflects the capacity of the BoC to keep the supply of overnight balances stable and close to zero, the small number of participants in the interbank market, and the real-time payments system, which leaves little payment uncertainty at the end of the day and thereby facilitates the matching of counterparties willing to close out unneeded positions at the target rate. Accordingly, the spread between the overnight rate and the floor of the corridor, displayed in exhibit $5 b$, has remained relatively constant over most of the past decade.

Since the Bank of Canada began targeting the floor of its corridor in April 2009, the ability of the deposit rate to provide a lower bound for the overnight interbank rate has been tested more significantly. During that period, the overnight rate routinely has traded a shade below the floor, the spread averaging 0.8 basis point and never exceeding two basis points. With leakage this small, the deposit rate floor could be seen as providing a reasonably substantial albeit not impermeable barrier for the overnight interbank rate. The CORRA, which only involves participants with access to the deposit facility, also has been trading at a shade below the deposit rate on most days since April 12, 2009. This benign amount of leakage likely reflects in part factors pertaining to the demand for Government of Canada securities. 


\section{Norges Bank}

Norges Bank operates an asymmetric corridor system in which the floor is determined by the sight deposit rate, the rate of interest paid on overnight deposits at the central bank's standing deposit facility. (See top panel of exhibit 6a.) All banks established in Norway can have a sight deposit account with Norges Bank and are able to earn the sight deposit rate on deposited funds. $^{21}$

The sum of banks' overnight deposits in accounts with Norges Bank, known as the banking system's liquidity, is typically managed so that the banking system as a whole has a net deposit position with Norges Bank overnight (bottom panel of exhibit 6a). The Bank relies on the excess of liquidity in the system to keep rates near the floor of its corridor. There are no reserve requirements.

\section{NIBOR}

A measure of next-day funding costs, called effective NIBOR, is published by Reuters and reported on Norges Bank's website. Like Libor, NIBOR is based on indicative rates of borrowing costs quoted by a panel of banks active in the Norwegian market. Because the participating banks typically quote large bid-ask spreads, actual transaction rates may often be closer to the floor than indicated by NIBOR.

Norges Bank also internally monitors rates derived from quotes on the Reuters Dealing trading platform of the Norwegian krone/ U.S. dollar tomorrow-next exchange rate and a corresponding tomorrow-next U.S. dollar interest rate. ${ }^{22}$ Because foreign banks established outside of Norway can trade on this platform, this measure implicitly includes the transactions of counterparties without access to sight deposit accounts at Norges Bank. Market disruptions during the financial crisis reportedly introduced sizeable measurement error to this internal measure, as it was unclear what rate banks trading on this platform faced for U.S. dollar funding.

\section{Balances during periods of tightening}

There is little evidence of a negative relation between the NIBOR and total liquidity balances held by banks at Norges Bank in the period prior to the crisis. From early 2002 to 2006, there was no trend growth or decline in total liquidity balances despite a significant easing of policy rates. There have been significant fluctuations around this long-run average, but in most cases these came with little apparent effect on rates, indicating that the "floor system" of keeping the market rate near the floor of the policy rate corridor has been largely successful.

\footnotetext{
${ }^{21}$ Norges Bank also has an automatic lending facility for banks, making overnight loans (D-loans) on request. The rate at which these loans are made serves as a ceiling for short-term money market rates. Since the interest rate on overnight D-loans is higher than short-term money market rates, a bank will not normally draw on overnight Dloans. Intraday D-loans are also available and can be used by the banks to obtain liquidity when settling payment transactions.

${ }^{22}$ Due to the unofficial status and relatively short history of this calculated series, we present effective NIBOR in exhibits $6 a$ and $6 b$.
} 


\section{Balances during the crisis}

As with most other central banks, rising demand for liquidity sent rates above target during the financial crisis. Norges Bank responded by engineering a large increase in total liquidity in late 2008, once again moving rates to just above its policy floor rate. After a period of substantial policy easing that ended in June, Norges Bank let liquidity run off as financial conditions improved and demand for liquidity became less acute. However, even at their low in October, balances were still elevated relative to early 2008, and they moved higher over the period surrounding the two sight deposit rate increases in October and December. This increase in balances during a period of policy tightening is consistent with the operation of a floor system and an absence of fine-tuning of the level of balances as long as they remain sufficient to keep market rates near the policy rate floor.

\section{Spread between NIBOR and the deposit rate}

Overall, Norges Bank's deposit facility appears to have been successful in creating a floor for short-term rates. The NIBOR has not fallen below the floor since 2001. (See exhibit $6 \mathrm{~b})$. The rates internally monitored by the Norges Bank have also tended to stay close to the corridor floor, but have occasionaly fallen below it in recent years. The fact that rates in the interbank market tend to be slightly above the sight deposit rate, rather than at the deposit rate or below, likely reflects in part the essentially risk-free nature of depositing funds with the central bank, compared with loans in the interbank market, which naturally have a greater degree of risk attached to them.

\section{Reserve Bank of Australia}

The framework used by the Reserve Bank of Australia (RBA) for the implementation of monetary policy is a corridor system centered on the RBA's target for the "cash rate," the interest rate on unsecured overnight interbank lending (exhibit 7a). The Reserve Bank sets rates for its standing loan and deposit facilities and makes frequent use of open market operations in both domestic and foreign currencies to manage the overnight rate.

Banks (and a number of other entities) hold Exchange Settlement accounts at the RBA to settle payments. The RBA has no prescribed target for the level of settlement balances but instead adjusts the supply to keep the cash rate near the target. The RBA pays interest on balances held in settlement accounts at a rate 25 basis points below the target for the cash rate. It is also prepared to provide liquidity on request to settlement account holders on an overnight secured basis at 25 basis points above the target for the cash rate.

\section{Cash rate}

Success in achieving the target for the cash rate is gauged through a daily survey of actual transactions recorded by around 20 out of the 50 or so banks with active settlement accounts; the 
survey participants comprise around $90 \%$ of daily flows through the RBA's Real-Time Gross Settlement system. ${ }^{23}$

\section{Exchange settlement balances during periods of tightening}

As shown in exhibit 7a, there is little evidence, if any, that increases in the target for the cash rate (upper panel) require an alteration in the level of aggregate balances in settlement accounts (lower panel). We identify four tightening episodes. First, the RBA tightened five times between November 1999 and August 2000, raising its target for the cash rate a total of 150 basis points. Aside from a temporary jump associated with the passage to the year 2000, aggregate balances declined moderately over that period, possibly as participating institutions became more accustomed to the real-time gross settlement system introduced in June 1998. Second, aggregate balances remained roughly constant as the RBA gradually increased its target rate a total of 200 basis points between 2002 and 2006. Third, the central bank hiked rates four times between August 2007 and March 2008. Rather than withdraw balances during that period, however, the RBA accommodated increases, as demand for liquid and risk-free balances evidently became larger and more volatile during the initial months of the financial turmoil.

The level of aggregate settlement balances remained elevated, as the monetary stance turned more accommodative in the second half of 2008, but has dropped off sharply in the past year even as policy rates moved lower. By the time the RBA announced in early October 2009 the first of a series of three hikes, settlement balances had fallen to their lowest level since August 2007. They continued to decline through the end of November, matching their pre-crisis level, before rising around year-end.

\section{Spread between the cash rate and the floor of the corridor}

As seen from exhibit $7 \mathrm{~b}$, the RBA has been very successful at keeping the overnight market rate spot on the official target. Deviations are rare events, even during the recent period of financial market stress, and since 2001, they have not exceeded more than a couple of basis points. As a result, the spread between the cash rate and the floor of the corridor has remained positive and extraordinarily stable during periods of monetary policy tightening and easing over the past ten years.

A number of elements contribute to this stability. One is the presence of a narrow and symmetric corridor around the target for the cash rate. A second is that the number of active participants in the overnight market is relatively low (15 to 20 active institutions), which facilitates the search for counterparties with offsetting positions. Moreover, participants openly disclose whether they are short or long on settlement balances and, by convention, generally trade overnight funds at the cash rate target. In addition, the RBA can adjust liquidity intraday if necessary or use moral suasion to encourage market participants to bring the overnight interbank rate back to target. Whether the deposit rate would provide an effective floor for the cash rate if

\footnotetext{
${ }^{23}$ The RBA also surveys banks about their overnight secured lending and borrowings. This survey currently has fewer than 10 respondents and includes activity undertaken with institutions that may not be banks. The survey generally picks up $\mathrm{A} \$ 10$ billion ( $\$ 8.6$ billion equivalent) in overnight government securities repo trades, compared with an estimated average of about $\mathrm{A} \$ 9$ billion ( $\$ 7.8$ billion equivalent) in the overnight unsecured market.
} 
liquidity were abundant is difficult to determine, given that no situation occurred in which the cash rate was allowed to trade near the floor over the period considered.

\section{Reserve Bank of New Zealand}

The Reserve Bank of New Zealand (RBNZ) implements monetary policy through its standing lending and deposit facilities (exhibit 8a) and through market operations, including foreign exchange swaps. The Reserve Bank's benchmark policy rate is its Official Cash Rate (OCR), and the central bank uses its policy tools to keep overnight interbank interest rates close to the OCR.

Institutions hold balances at the RBNZ to meet settlement needs, which must be met without resort to intraday credit from the central bank. There are no required reserves. As of early 2008, 12 registered banks, the vast majority of which were foreign owned, maintained accounts with the central bank. ${ }^{24}$ Overnight holdings are remunerated at the OCR up to a fixed limit, or "tier," which is set by the central bank, specific to each institution, and primarily based on likely tail-event settlement needs. Balances held in excess of the limit earn interest at a rate equal to the OCR less 100 basis points. Thus, balances in excess of the tier are similar to excess reserves or balances placed at the standing deposit facilities of other central banks. By offering a relatively low return on excess balances, the Reserve Bank's rate structure is designed to discourage holdings of central bank balances beyond what is needed for settlement purposes, to encourage interbank cash market activity and bank holdings of liquid instruments other than central bank balances.

The current framework is the result of a decade of experimentation aimed at improving liquidity in the interbank market for overnight funds. In 1999, the RBNZ abandoned a system in which monetary policy was implemented through a target for the quantity of settlement balances in favor of a corridor system with the OCR at its core. The central bank remunerated all overnight holdings of settlement balances at 25 basis points below the OCR, while secured overnight loans were offered on demand at 25 basis points over the OCR. In this regime, demand for overnight balances was low, as banks relied heavily on intraday liquidity provided by the RBNZ to meet their payments and settlement needs.

In reaction to signs that liquidity provision was not fully adequate under this system, the Reserve Bank changed its operating framework in 2006 by "cashing up," which involved substantially increasing settlement balances and simultaneously phasing out its provision of daylight credit. ${ }^{25}$ The transition to the new system was implemented from July through October 2006, and to encourage banks to hold balances, the Reserve Bank shifted to remunerating all overnight balances at the OCR, rather than at 25 basis points below the OCR. As a result,

\footnotetext{
${ }^{24}$ The RBNZ also deals with counterparties that do not have a reserves account. Most of them are Australia-based banks with a presence in the foreign exchange market and occasional liquidity needs. These entities could request a reserve account at the RBNZ.

${ }^{25}$ Evidence of problems with the availability of liquidity under the earlier system included a notable increase in demand for intraday liquidity when collateral rules were relaxed, high demand for government securities, a relatively high incidence of delayed, just-in-time, or failed settlements, frequent use of the standing facilities, underbidding at the Reserve Bank's open market operations, and significant variations between the domestic overnight interbank rate and the overnight rate available in the foreign exchange swap market.
} 
between October 2006 and August 2007, the RBNZ operated an asymmetric corridor, with the OCR at the corridor floor (that is, the OCR and the rate at the standing deposit facility were identical). ${ }^{26}$

Experience with this system revealed hoarding of balances by some banks, and the RBNZ responded in late August 2007 by implementing the tiering system mentioned above. Along with the introduction of the tiering system, the deposit rate for reserves in excess of each bank's tier limit was lowered to 100 basis points below the OCR, to reduce the return to holding excess reserves. $^{27}$

\section{Overnight interbank rates}

The Reserve Bank currently monitors closely two indicators of rates in bank funding markets. One is the overnight interbank cash rate (OICR). The OICR is the average interest rate of secured and unsecured overnight cash transactions reported in a daily survey of domestic price makers. All respondents have reserves accounts at the central bank, and the rates quoted cover only transactions among respondents. In recent years, unsecured transactions have represented about 80 percent of the volume of overnight lending. ${ }^{28}$

Since the implementation of "cashing up," domestic interbank trading has declined. As a result, the RBNZ monitors a range of rates, particularly the implied overnight foreign exchange swap rate. The overnight foreign exchange swap market is quite active and has a range of onshore and offshore participants, especially in London. The RBNZ mainly used foreign exchange swaps to inject liquidity, but during the most stressed periods of the crisis it reverted to domestic open market operations with repurchases.

\section{Balances at the RBNZ during periods of tightening}

We distinguish four main episodes characterized by multiple OCR hikes over our sample period: November 1999 to May 2000 (+200 basis points), March to July $2002(+100$ basis points), January 2004 to March 2005 (+175 basis points), and March to July 2007 (+100 basis points). ${ }^{29}$ As suggested by exhibit 8 a, there is no evidence that settlement balances systematically declined over these tightening episodes, with the medium-term behavior of the balances appearing largely unrelated to movements in policy rates up or down, both before and after the banking system was "cashed up."

With settlement balances relatively abundant and the OCR at the floor of the corridor, the operating framework during the 2007 episode closely resembles a "floor system." However, the extent to which the supply of balances was in excess of demand during that period is not clear, given the significant boost to demand for overnight balances following the elimination by the RBNZ of provision of intraday liquidity.

\footnotetext{
${ }^{26}$ The new regime also altered the formula for the rate on funds obtained from the standing loan facility, which moved up to 50 basis points over the OCR by October 2006. This new formulation preserved the 50 basis point spread between the rate of remuneration of cash balances and the rate paid on borrowing from the central bank. ${ }^{27}$ The rate at the standing lending facility remained at 50 basis points over the OCR.

${ }^{28}$ Most participants in the overnight market have accounts at the RBNZ, although not everyone currently does.

${ }^{29}$ A brief fifth episode can be identified as well. In late 2005 there were two rate hikes of 25 basis points each. Settlement balances were volatile over that short tightening episode.
} 


\section{Balances at the RBNZ during the crisis}

In response to the decline in demand for balances following the introduction in August 2007 of the tiered remuneration system, the RBNZ was able to reduce the overall quantity of settlement balances while keeping overnight market rates stable. Subsequently, as the financial crisis intensified, the demand for settlement balances rose, which the RBNZ accommodated largely by injecting liquidity through foreign exchange swaps with a maturity of three months.

With the normalization of financial markets in 2009, the Reserve Bank was able to reduce balances again, even as it continued to lower the OCR.

\section{Spread between overnight interbank rates and the policy rate floor}

The spread between the OICR and the policy rate floor, shown in the upper panel of exhibit $8 \mathrm{~b}$, has been volatile since the elimination of daylight overdrafts and the switch to the "cashed up" regime in 2006. Nonetheless, the OICR has remained well above the floor set by the remuneration of excess reserves. ${ }^{30}$ Even during the tightening in 2007, when the OICR was near the policy rate floor, the spread remained strictly positive, perhaps reflecting a positive risk premium priced into the OICR that was keeping it above the risk-free deposit rate floor. In addition, the Reserve Bank may have been reluctant to let the OICR move so close to the OCR that it might seriously constrain activity in the interbank market, an explanation consistent with the introduction of the tiering system in August 2007 that encouraged interbank lending. As shown in the bottom panel, the overnight cost of funds from the foreign exchange swap market, which covers transactions by lenders that do not have access to the RBNZ's deposit facility, showed even more volatility than the OICR and at times slipped below the deposit rate.

\section{Riksbank}

The Riksbank uses its standing facilities and open market operations to guide the shortterm interbank interest rate towards a target set by the Executive Board of the Bank (exhibit 9a). The Riksbank uses its repo rate to signal where policymakers wish the market rate to be.

The RIX payment system provided by the Riksbank is the hub of the Swedish interbank market. There are currently 21 counterparties that participate in the RIX system. In addition to banks, participants include mortgage and other credit institutions, the government debt office, and clearing houses. Of the participants in the RIX, 14 are Monetary Policy Counterparties and 5 are Primary Monetary Policy Counterparties. Only Monetary Policy Counterparties participate in the Riksbank's standing facilities or its weekly monetary open market operations ( 7 of the 14 participate in the weekly operations), and only Primary Monetary Policy Counterparties participate in its fine-tuning operations (that is, open market operations). ${ }^{31}$

\footnotetext{
${ }^{30}$ There are two instances of negative spreads in the official data early in the sample period, both of which occurred on days of OCR target hikes. They may reflect the recording of overnight transactions before the target announcements, in which case they would not be indicative of leakage.

${ }^{31}$ In April 2009, the Riksbank further widened its set of counterparties, by allowing credit institutions with registered offices in Sweden to become Restricted Monetary Policy Counterparties, giving them access to its collateralized loans of Swedish kronor at variable interest rates and to purchases of Riksbank certificates.
} 
The Riksbank does not impose reserve requirements. Before the payment system closes each day, banks' accounts in the Riksbank's payments system must be balanced. If necessary, banks can achieve this by borrowing or depositing funds at the Riksbank overnight through the central bank's marginal lending and deposit facilities. The deposit rate, the rate paid on balances placed in the marginal deposit facility, is normally 75 basis points below the repo rate, while the lending rate, the rate charged at the marginal lending facility, is normally 75 basis points above the repo rate. The Bank narrowed the corridor to \pm 50 basis points on April 22, 2009, when it cut its repo rate to $1 / 2$ percent, thus setting the deposit rate to 0 percent. As of July 8,2009 , the Riksbank cut the repo rate to $1 / 4$ percent but retained the corridor of \pm 50 basis points, setting the deposit rate to $-1 / 4$ percent.

Although rates are generally well above the deposit rate, banks have continued to make some modest use of the deposit facility, depositing 70 million kronor (equivalent to less than $\$ 10$ million) in the facility. Even after the deposit rate became negative in July, banks continued to use the deposit facility. ${ }^{32}$

\section{STIBOR}

The chief measure of short-term interbank rates in Sweden is the STIBOR (the Stockholm Interbank Offered Rate, displayed in the upper panels of exhibit 9a), a next-day rate. $^{33}$ As with LIBOR, this represents a trimmed mean of rates for uncollateralized borrowing reported by major commercial banks in the market, and thus is not based on actual transactions.

\section{Balances at the Riksbank during periods of tightening}

As can be seen in the lower left panel of exhibit 9a, prior to the recent financial crisis, balances at the Riksbanks were quite small. In fact, on many days there were no balances held at the central bank, so that overall there seems to have been little or no link between balances and the level of the policy rate. During the brief period of tightening in 2002, the average quantity of balances held at the Riksbank rose somewhat. Over 2006-08, when the Bank raised its repo rate from 1.5 percent to 4.75 percent, average deposits held at the bank fluctuated within a fairly tight range and showed no real trend up or down.

\section{Balances at the Riksbank during the crisis}

As the financial crisis intensified in October of 2008, the Riksbank began to issue longerterm loans in Swedish krona to help alleviate pressures in term funding markets. For a shorttime in early October 2008, these funding pressures pushed the STIBOR above the rate offered at the Riksbank's overnight lending facility. However, STIBOR quickly fell below the lending rate

\footnotetext{
${ }^{32}$ Although larger use of the facility was made at the end of December 2008 and during the week of April 23, 2009, immediately after the Riksbank cut its repo rate to 50 basis points and narrowed the corridor, even this amounted to 700 million kronor (roughly $\$ 100$ million equivalent) and likely represents a miscalculation by one or more banks as to the amount they needed to offer at a fine-tuning operation. In these instances, the amounts in the deposit facility were dwarfed by the equivalent of more than 85 billion kronor (about $\$ 12$ billion equivalent) in fine-tuning operations.

${ }^{33}$ Short-term funding (funding with maturities ranging from overnight to up to a week) in Sweden is primarily obtained through unsecured interbank deposit contracts, repurchase agreements, or foreign exchange swap arrangements, with the three types of arrangements comprising roughly equal shares of total activity.
} 
after the auctions of term funds began, and overnight balances held with the Riksbank moved up sharply. Thereafter, the Riksbank accommodated the elevated demand for liquidity at market rates close to the center of its policy rate corridor, relying on fine-tuning operations to keep the market rate from deviating substantially from that position.

Spread between STIBOR and the deposit rate

As shown in the upper panels of exhibit 9a, short-term interest rates have generally remained quite close to the center of the corridor. As shown in exhibit 9b, rates have remained well above the deposit rate. While the standing facilities are an important component of the monetary framework, on a day-to-day basis the relative stability of short-term rates in recent years can be attributed to the Riksbank's frequent fine-tuning operations. 


\section{Appendix 2}

\section{Corridor systems and policy tightening: How raising the rate of interest on reserves can lift market rates without reductions in reserve balances}

Until October 2008, the Federal Reserve could be viewed as operating a kind of corridor system in which the discount rate or the primary credit facility rate formed the top of the corridor and a fixed interest rate of zero was the bottom. A key feature that distinguished this corridor from those employed by many other foreign central banks was the fixed floor rate, which meant that the size of the corridor varied with the official lending rate and monetary policy operations chiefly focused on altering the aggregate supply of reserve balances to target the federal funds rate within the corridor.

In more conventional corridor systems with adjustable floor rates, central banks also use variations in the aggregate supply of balances to target rates within the corridor, but they have as well the option of using adjustments in the position of the corridor to influence demand for balances. Because changes in policy rate targets are typically made along with comparable adjustments in both ceilings and floors of corridors, adjustments in the supply of central bank balances are not needed to influence market rates. Central banks may nonetheless conduct finetuning operations to manage the market rate more tightly within the corridor, responding to shifts in demand factors or changes in autonomous factors that can shift aggregate supply of central bank balances available to the banking system.

A variant on the corridor system with the adjustable floor is the so-called "floor system," as described in Keister et al. (2008) and in Goodfriend (2002). In this system, central bank balances are supplied in excess of what is necessary to keep the market rate at the floor of the corridor. The emphasis of policy operations, at least for managing the day-to-day market rate, shifts from fine-tuning operations that influence the supply of balances to ensuring that the supply is large enough to keep the interbank rate at the floor rate of the corridor: the floor rate becomes the signal of the stance of policy. As long as the supply of balances remains in excess, limited variations in supply may have no effect on the market rate because the downward movement of the market rate is constrained by the corridor floor. Thus, fine-tuning operations to influence reserves may not be necessary to keep the market rate near the policy target in this case. ${ }^{34}$ This variant relies almost exclusively on the floor and possibly market incentives for arbitrage to keep the market rate near the policy rate target. Goodfriend (2002) argues that using the rate of interest on balances as a policy tool in such situations can increase a central bank's power to influence the market interest rate independently of the quantity of reserves. Keister et al. (2008) make a similar point.

In principle, transmission of a policy tightening works the same way in either the standard corridor system with an adjustable rate floor or in the floor system variant. ${ }^{35}$ Raising

\footnotetext{
${ }^{34}$ Fine-tuning operations may still be used by a central bank with a floor system if the central bank has a target for excess reserves, as the Bank of Canada does currently.

${ }^{35}$ Woodford (2000) provides an analysis, taking the operation of monetary policy in New Zealand as an example. See also Whitesell (2006) and Keister et al. (2008) for analysis and discussion of interest on reserves and monetary policy in New Zealand and other foreign economies.
} 
the rate of interest on excess reserve balances prompts an increase in demand for balances as institutions respond to the change in the configuration of returns available. When a central bank raises the rate of interest on reserves, banks will attempt to shift the composition of their assets toward central bank accounts and away from other investments, such as loans and securities. In the aggregate, of course, banks will not be able to increase holdings of balances at the central bank, but sales of securities will put upward pressure on yields and bank lending will contract. These effects are similar to those that would occur when rate hikes involve operations to drain reserve balances, but in this case the central bank tightens monetary policy without selling assets, issuing debt, or otherwise altering central bank balances outstanding. No change in the size of the central bank's balance sheet is needed, although full adjustment to the change in policy may induce some long-run adjustment in specific balance sheet accounts; for example, as economic activity slows, reservable deposits may decline and in that case excess reserves would increase.

Exhibit 10 provides a simple graphical comparison of how tightening monetary policy with and without adjusting the interest rate paid on reserves influences the need to reduce reserves to support the policy tightening. This exercise starts with a simple stylized model of the market for balances at a central bank. We make the conventional assumption that the demand for balances, DD, depends inversely on the opportunity cost of holding balances. We characterize this opportunity cost as the interest rate that could be earned on lending balances in the market minus the interest rate paid by the central bank on balances $r_{c b}$. When the spread between the market rate and $r_{c b}$ decreases, earnings opportunities in the market decline relative to those at the central bank, and demand for balances rises. As the spread approaches zero, the opportunity cost of holding balances vanishes, and banks become willing to absorb considerable increases in balances at only slightly lower opportunity costs.

For a given value of $r_{c b}$, say $r_{c b}=0$, the demand for balances can be represented as function of the market rate only, as shown in the top left panel of the exhibit. When the central bank targets a specific market rate $r$, the demand curve shows the quantity of balances $q$ that banks would willingly hold at the central bank. We assume this quantity reflects demands arising from the need to meet settlement obligations, which may include precautionary demand, and reserve requirements, if any. As shown in the panel, an increase - in this example of 50 basis points - in the target rate to r' prompts the equilibrium quantity of balances demanded to fall to q'. We assume that the new equilibrium quantity of balances demanded incorporates the long-run adjustment of the economy to the higher market rate, including any adjustment of economic activity and reservable bank deposits, which could affect settlement needs or reserve requirements. Thus, in the long run, to support the interest rate increase, the central bank would need to reduce the quantity of balances supplied to banks by q-q'.

The panel to the top right shows the same increase in the target for the market rate when the initial target rate is very close to $r_{c b}$ and central bank balances are abundant. The decrease in the quantity of balances demanded is larger in this case, indicating that the central bank would need to drain a considerably larger quantity of balances to achieve the same increase in the target for the market rate from this initial condition.

The bottom left panel shows how an increase in the target for the market rate would affect the equilibrium quantity of reserves demanded in the base case if the central bank also increased the rate of interest paid on balances. In this case, in addition to the adjustments 
described in the top left panel, the demand curve shifts out to DD', since for each market interest rate the opportunity cost of holding reserves is smaller when $r_{c b}$ increases to $r_{c b}$ ' (where $r_{c b}{ }^{\prime}=0.5$ ). In this simple model, the demand curve would shift up vertically by the amount of the increase $r_{c b}$ ' $r_{c b}$, leaving the quantity demanded in equilibrium unchanged at $q$. In practice, the shift up in the demand for balances may not be precisely equal to the increase in policy rates, but as long as the demand for central bank balances increases at all, the need to reduce central bank balances to achieve the higher target rate will be smaller in this case.

The bottom right panel shows that even when the initial target rate is very close to $r_{c b}$, the increase in $r_{c b}$ prompts a shift up in the demand for central bank balances that can reduce the need to drain balances to support the increase in the target interest rate. 


\section{References}

Bank of Canada, “Monetary Policy Report,” April 2009.

Bank of Canada, "Operating Framework for the Implementation of Monetary Policy at the Effective Lower Bound for the Overnight Interest Rate," April 21, 2009.

Borio, Claudio, "Monetary Policy Operating Procedures in Industrial Countries," BIS Working Papers No. 40, March 1997.

Clinton, Kevin, "Implementation of Monetary Policy in a Regime with Zero Reserve Requirements," Bank of Canada Working Paper 97-8, April 1997.

Engert, Walter, Toni Gravelle, and Donna Howard. "The Implementation of Monetary Policy in Canada," Bank of Canada Discussion Papers 2008-9, July 2008.

Goodfriend, Marvin, "Interest on Reserves and Monetary Policy," FRBNY Economic Policy Review, Vol. 8, No. 1 (May), pp. 13-29, 2002.

Groom, John and Ian Nield, "Implementing Monetary Policy in New Zealand," unpublished paper, Reserve Bank of New Zealand, February 2008.

Howard, Donna, "A Primer on the Implementation of Monetary Policy in the LVTS Environment," Bank of Canada, 2007.

Keister, Todd, Antoine Martin, and James McAndrews, "Divorcing Money from Monetary Policy,” FRBNY Economic Policy Review, Vol. 14, No. 2 (September), pp. 41-56, 2008.

Nield, Ian, "Evolution of the Reserve Bank's liquidity facilities," Reserve Bank of New Zealand: Bulletin, Vol. 71, No. 4, December 2008.

Nield, Ian, "Changes to the liquidity management regime," Reserve Bank of New Zealand: Bulletin, Vol. 69, No. 4, July 2006.

O'Brien, Yueh-Yun C., "Reserve Requirement Systems in OECD Countries," Finance \& Economics Discussion Series, 2007-54, Federal Reserve Board, Washington, DC, 2007.

Reid, Christopher, "The Canadian Overnight Market: Recent Evolution and Structural Changes," Bank of Canada Review, Spring 2007.

Reserve Bank of New Zealand. "Reform of the Reserve Bank of New Zealand's Liquidity Management Operations," Reserve Bank of New Zealand, June 2006.

Whitesell, William, "Interest Rate Corridors and Reserves," Journal of Monetary Economics 53 (September), pp. 1177-1195, 2006.

Woodford, Michael, "Monetary Policy in a World Without Money," International Finance 3, No. 2 (July), pp. 229-60, 2000. 
Exhibit 1a

Federal Reserve

\section{Overnight Interest Rate}
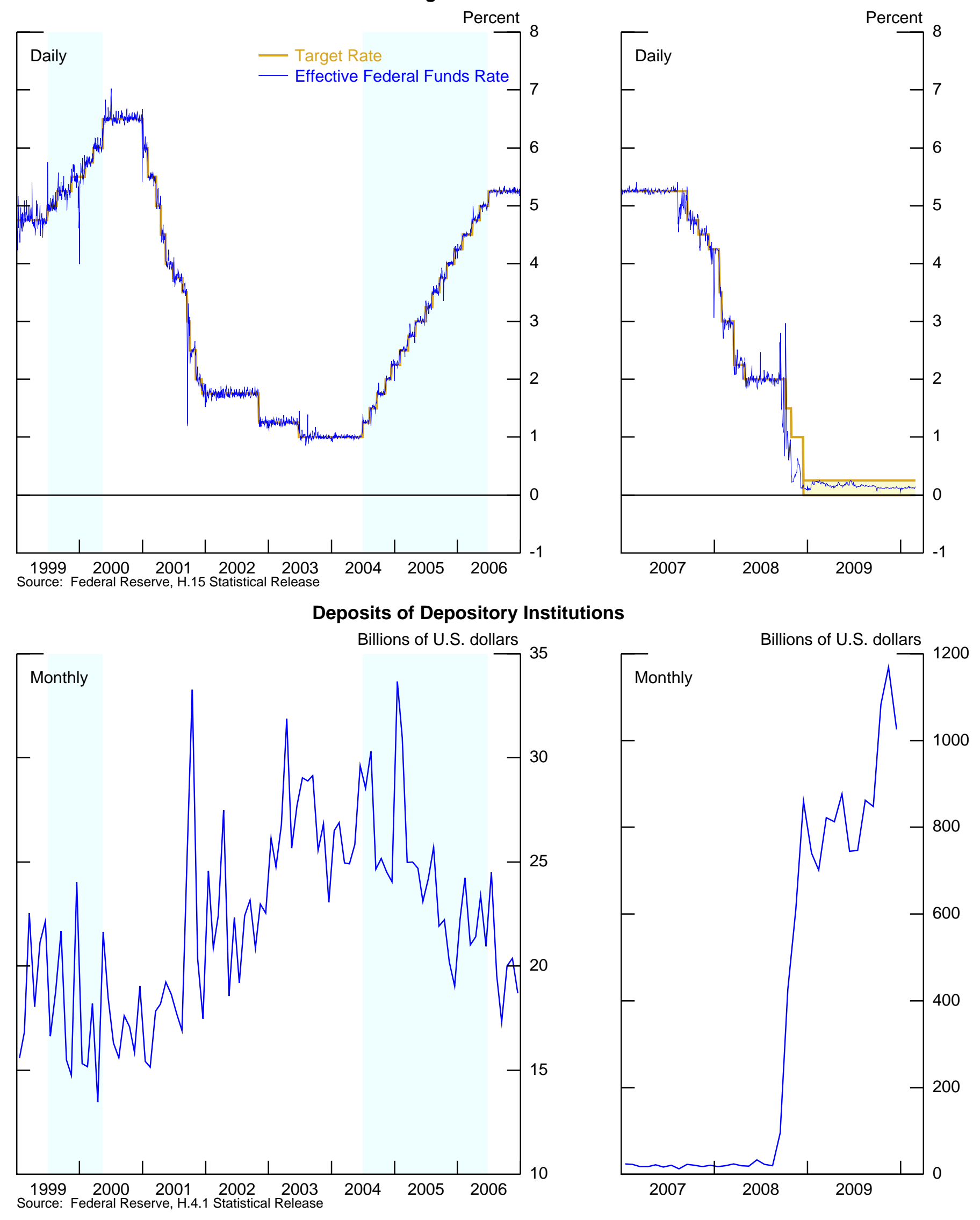
Exhibit 1b

\section{Federal Reserve}

Spread

Effective Federal Funds Rate - Interest Rate on Excess Reserves*

Daily

(1)

$-$

\begin{tabular}{|}
\hline \\
\hline
\end{tabular}

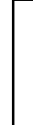

$-$

$1999 \quad 2000 \quad 2001$ 2002 2003

2004

2005

2006

2007

2008

2009 
Exhibit 2a

\section{European Central Bank}

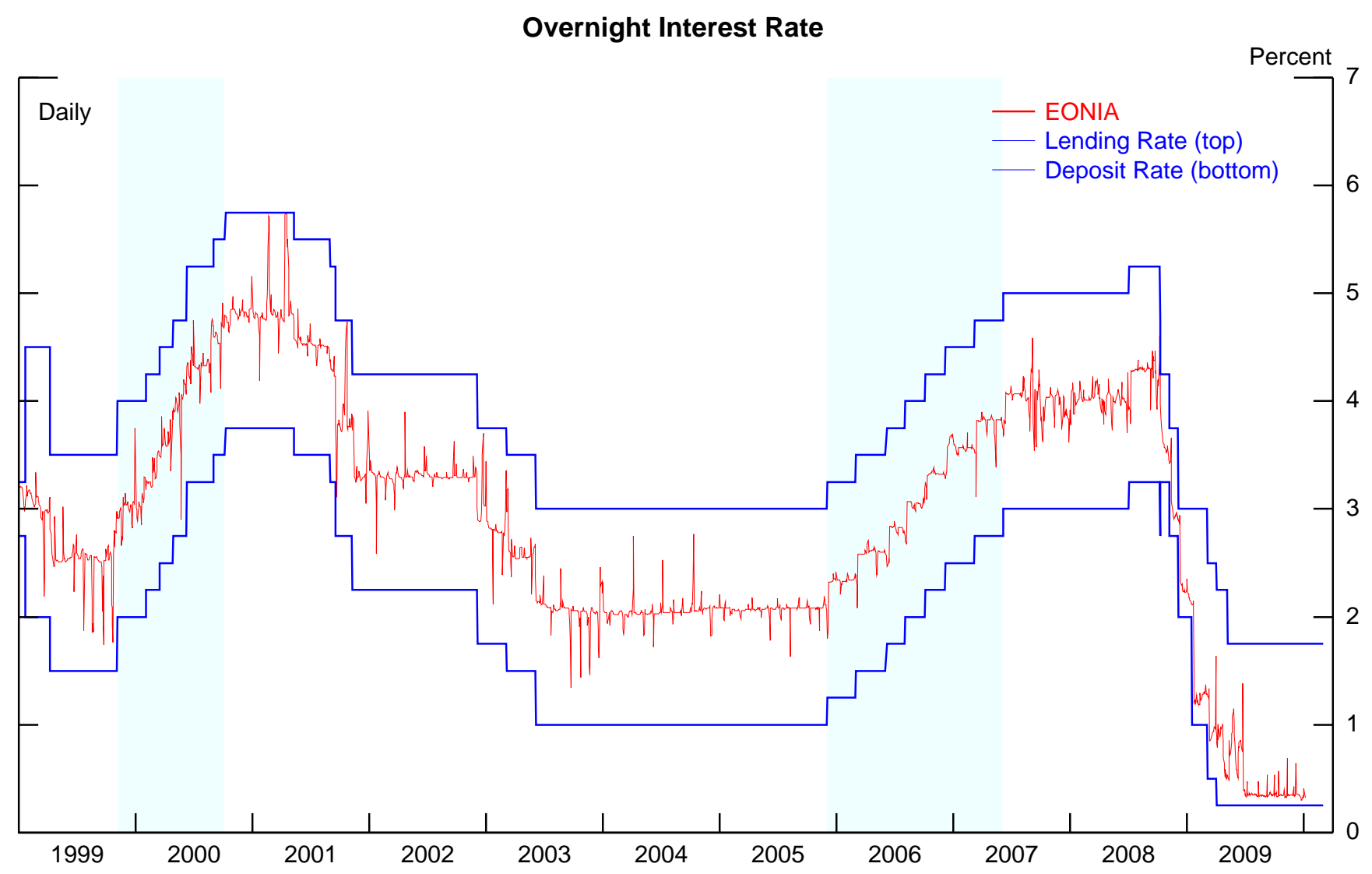

Balances in Current Accounts and Deposit Facility

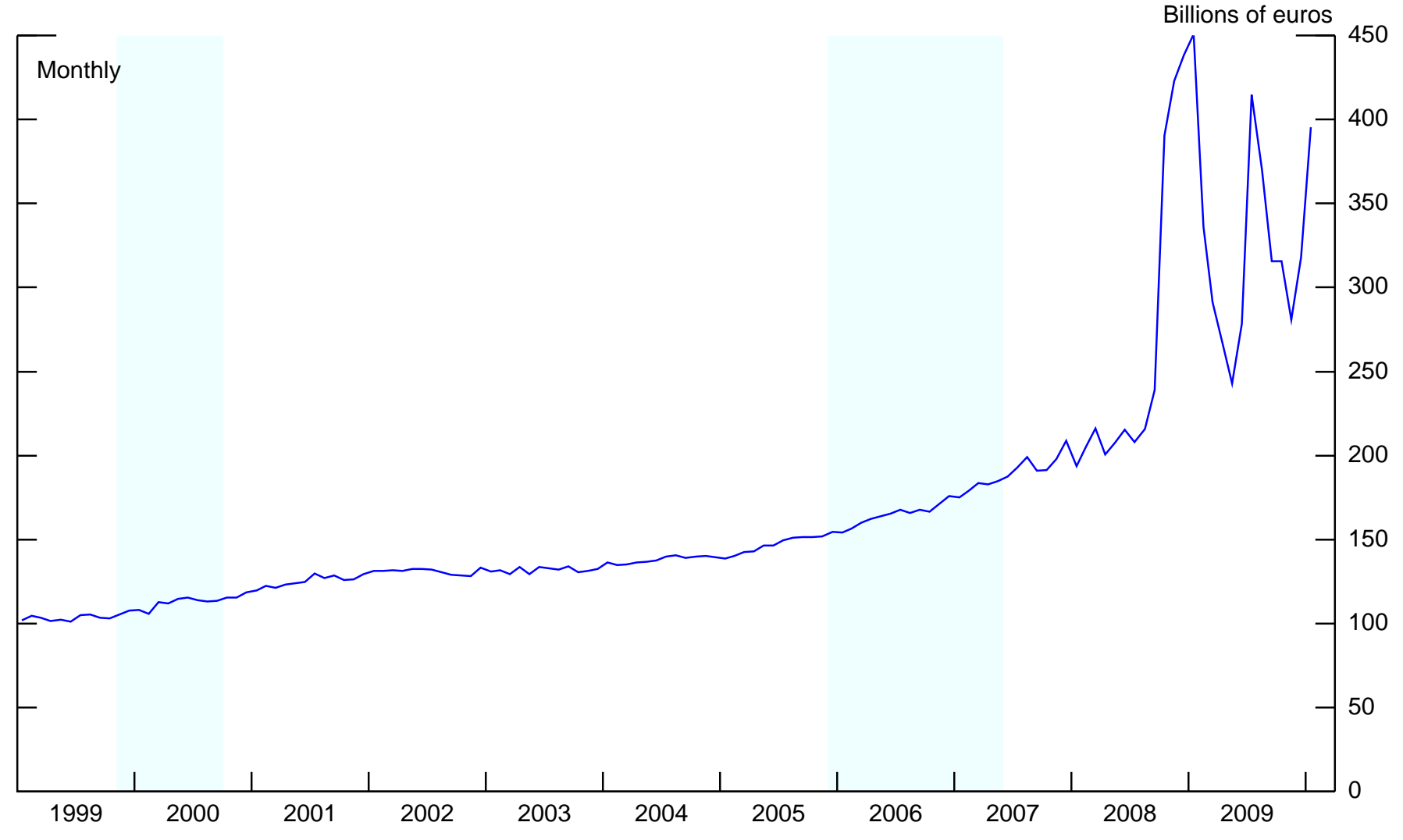


Exhibit $2 b$

\section{European Central Bank}

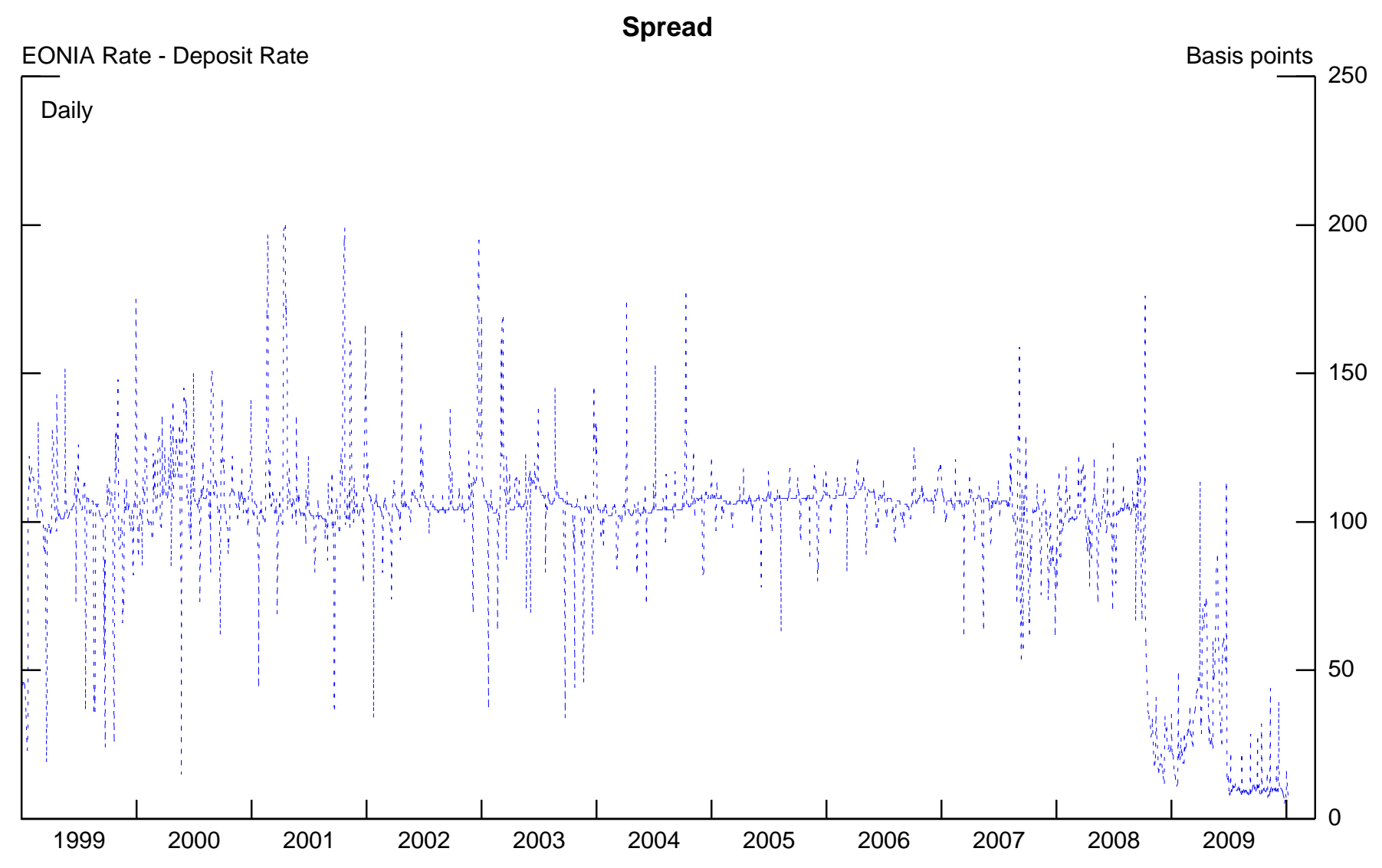




\section{Bank of Japan}

\section{Overnight Interest Rates}

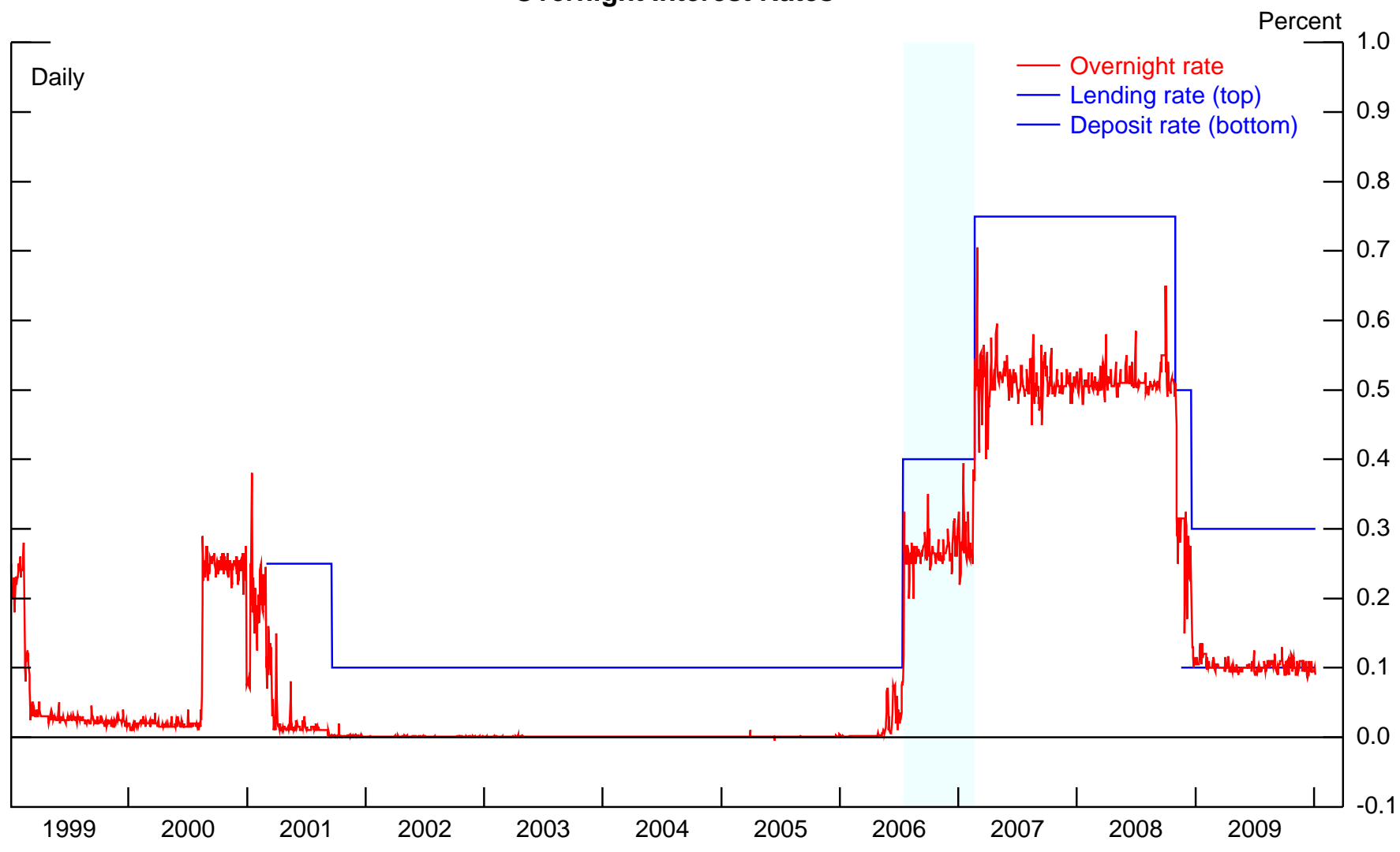

Current Account

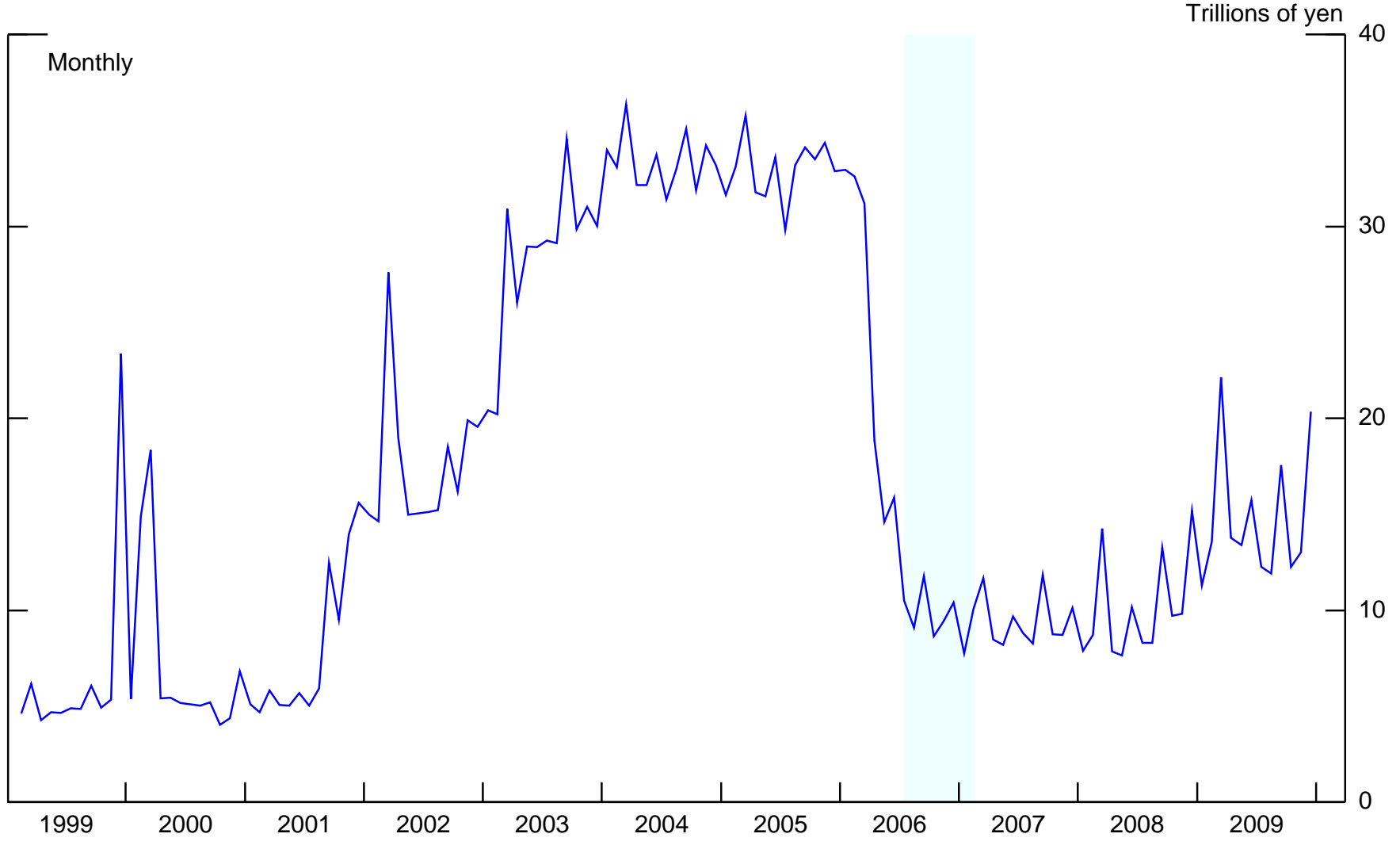


Exhibit 3b

\section{Bank of Japan}

\section{Spread}

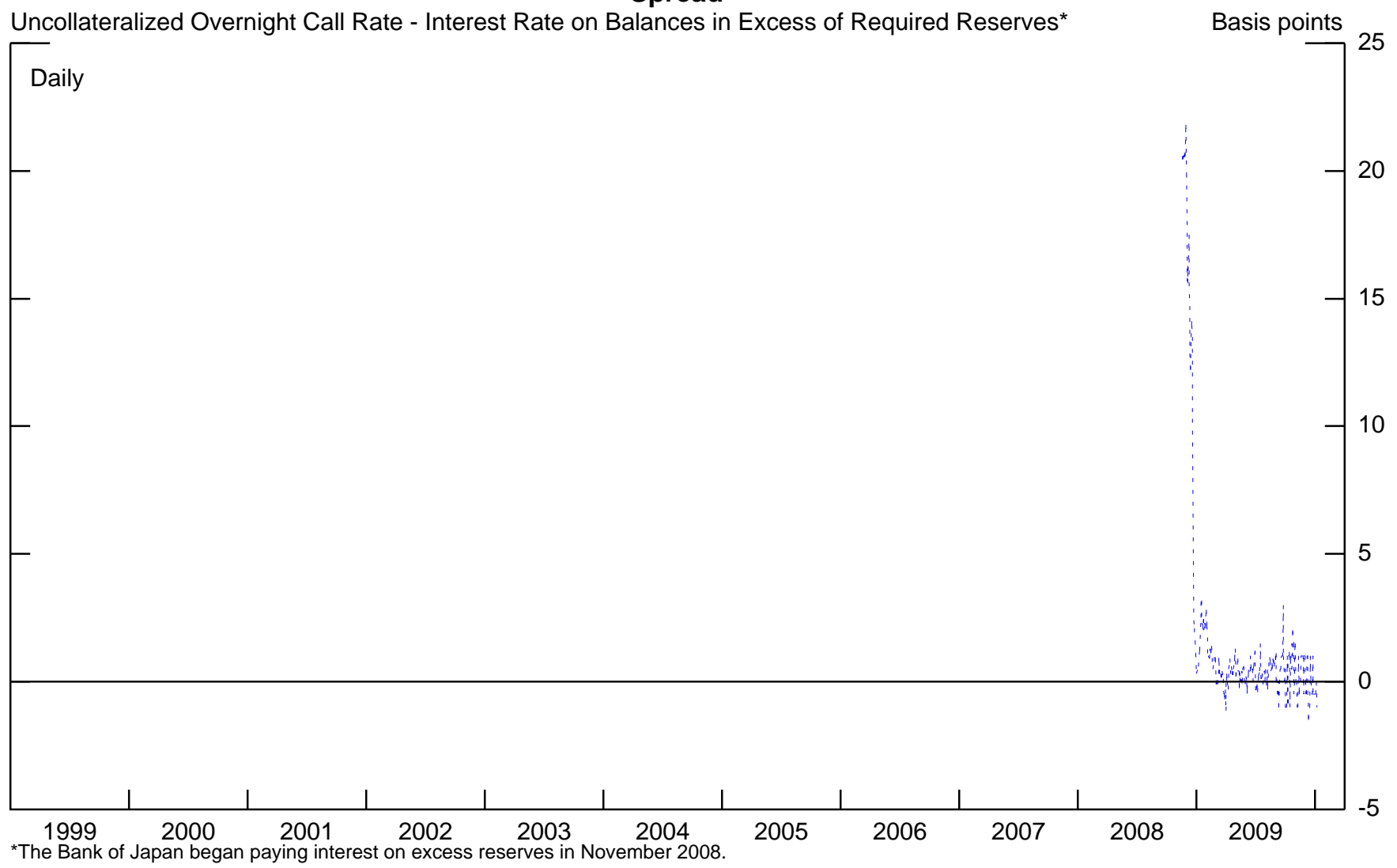


Exhibit 4a

\section{Bank of England}

\section{Overnight Interest Rate}

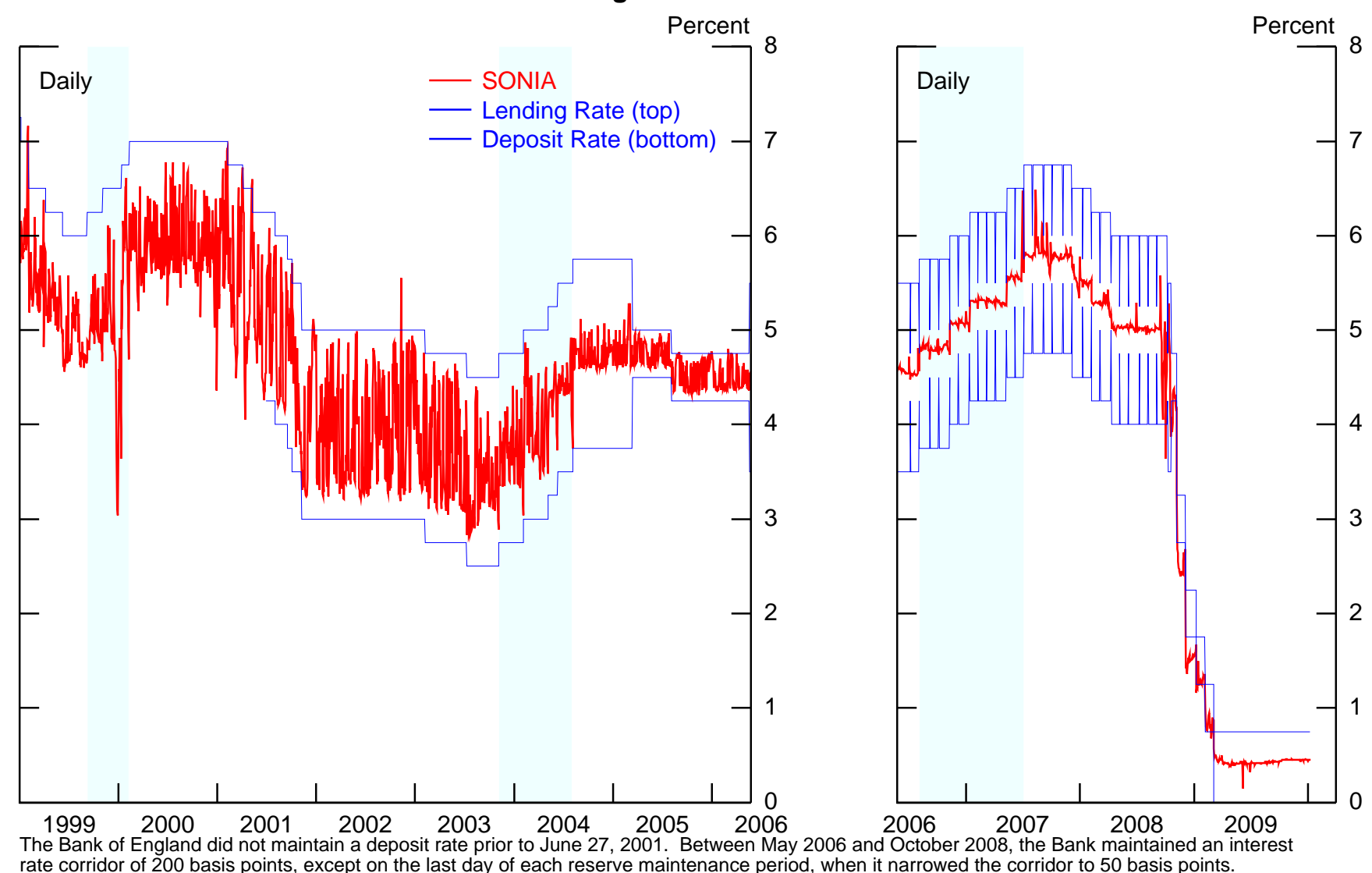

Reserve Balances

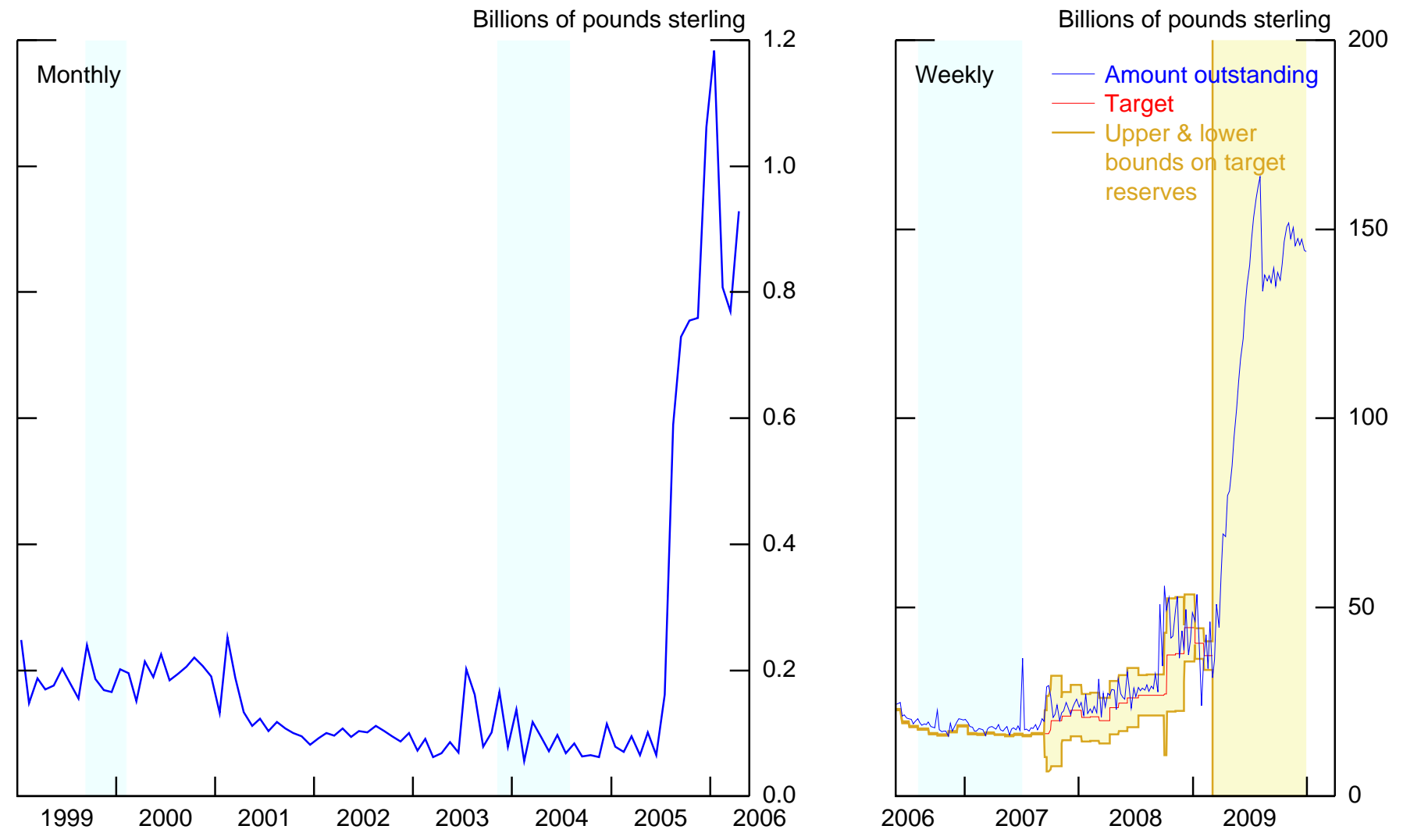


Exhibit 4b

\section{Bank of England}

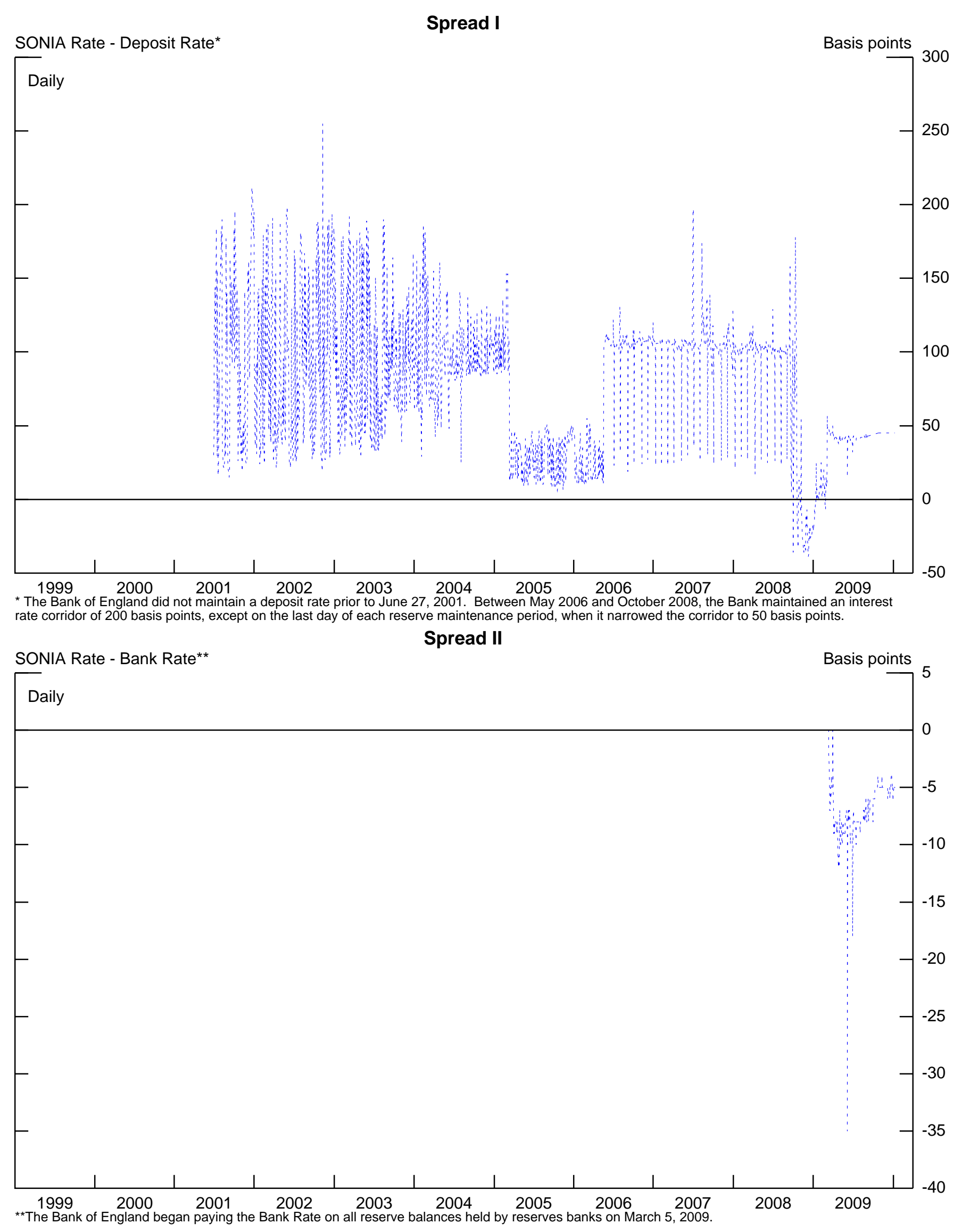


Exhibit 5a

Bank of Canada

Overnight Interest Rate

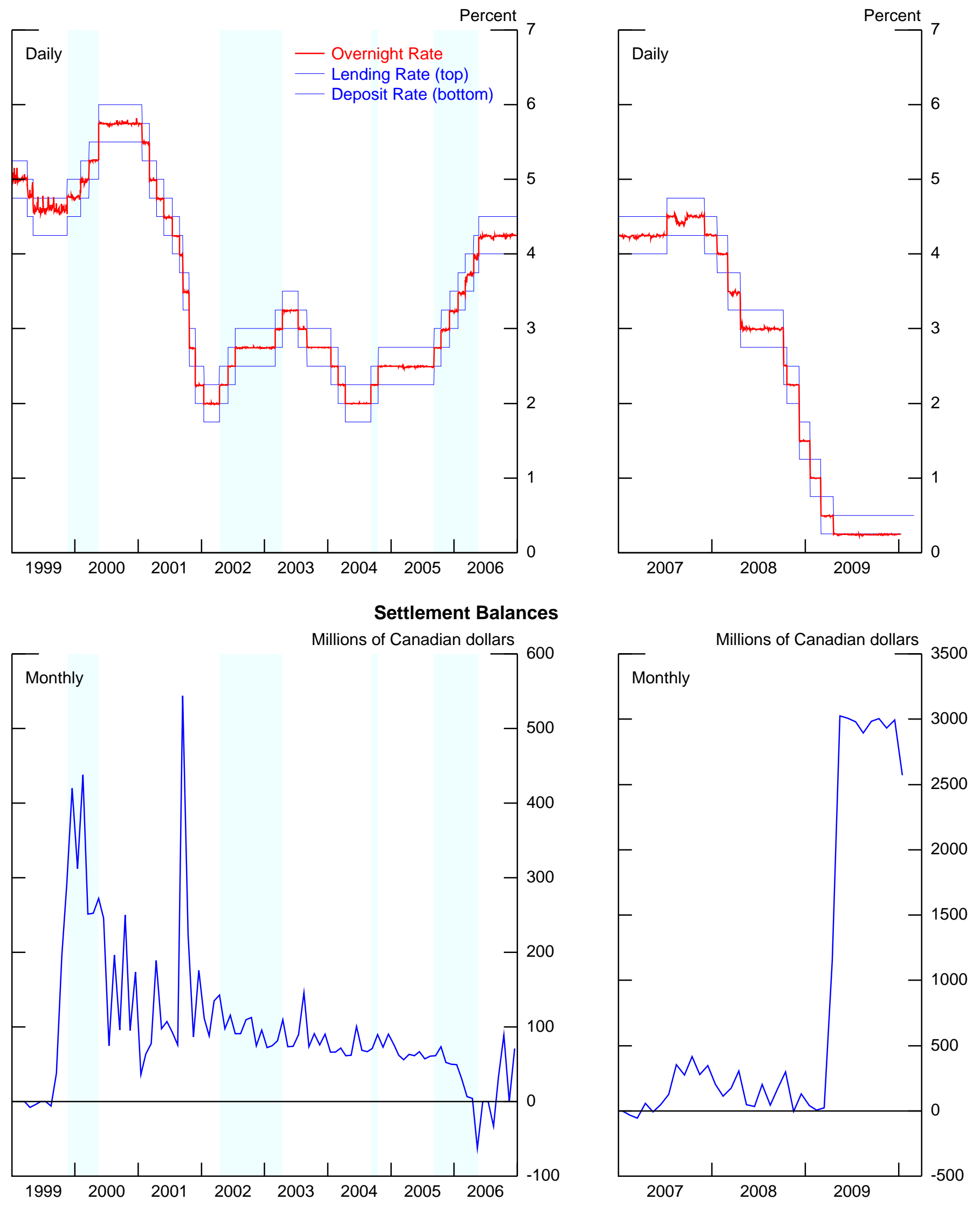


Exhibit 5b

\section{Bank of Canada}

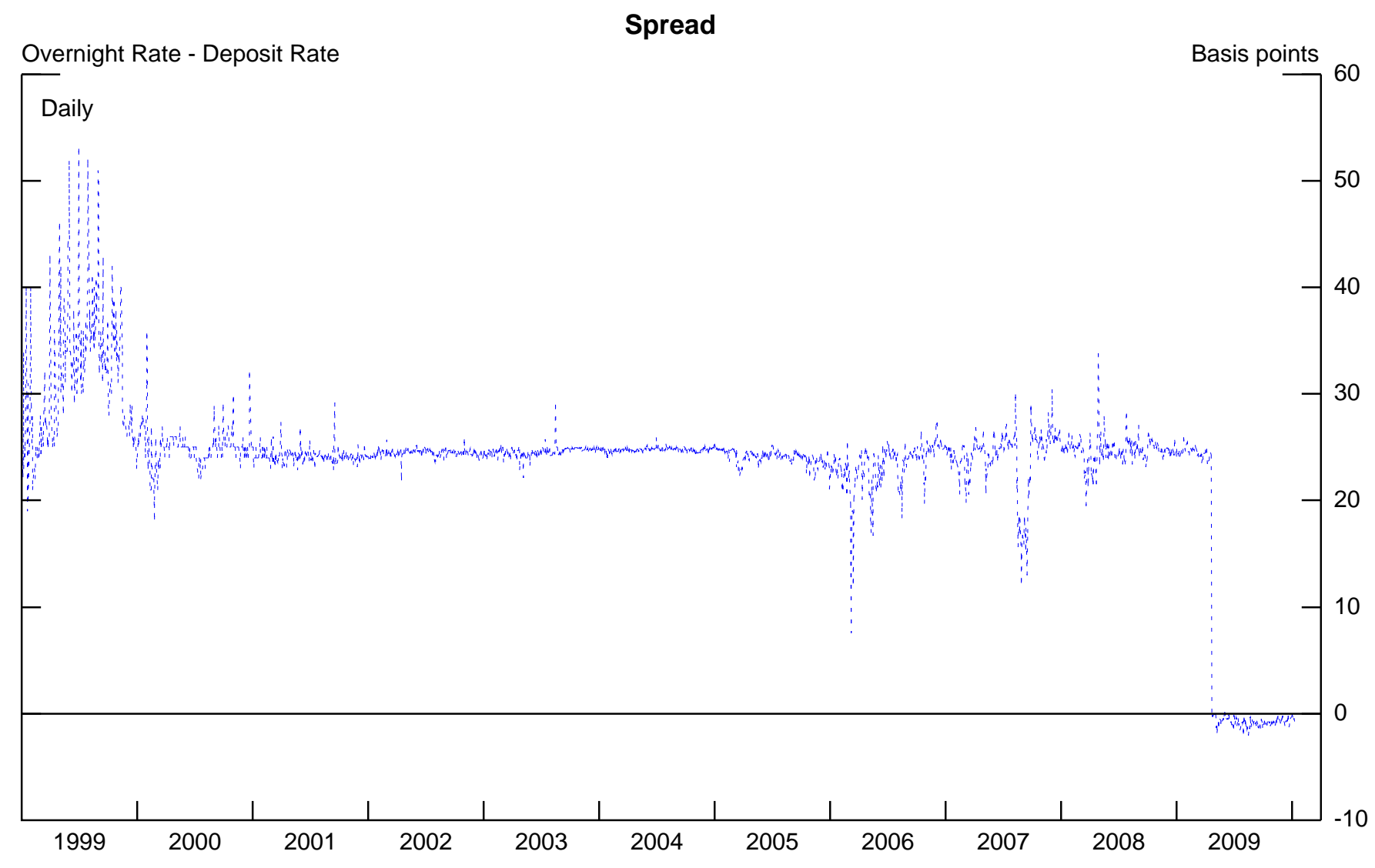


Exhibit 6a

\section{Norges Bank}

\section{Overnight Interest Rates}

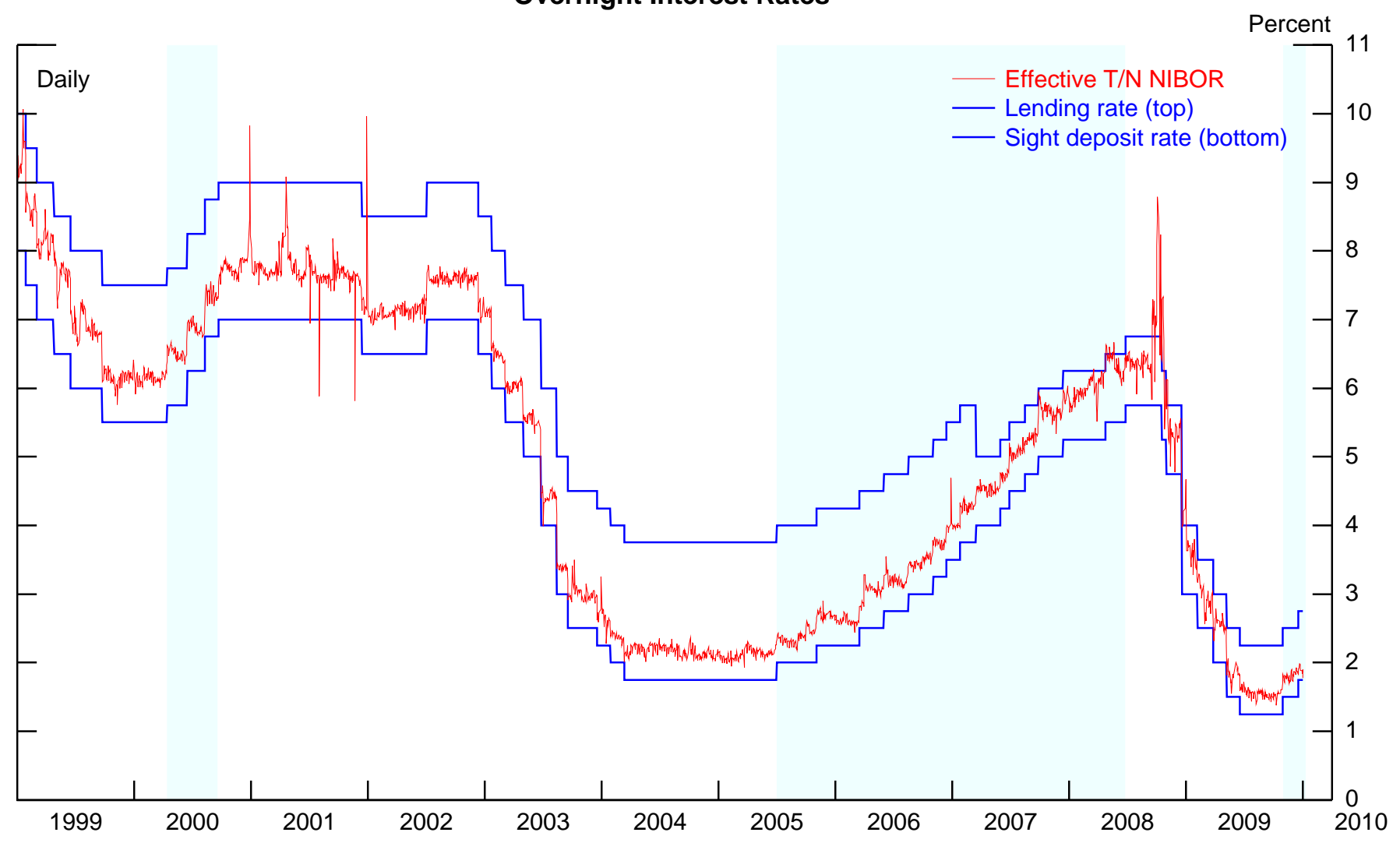

Total Liquidity Balances

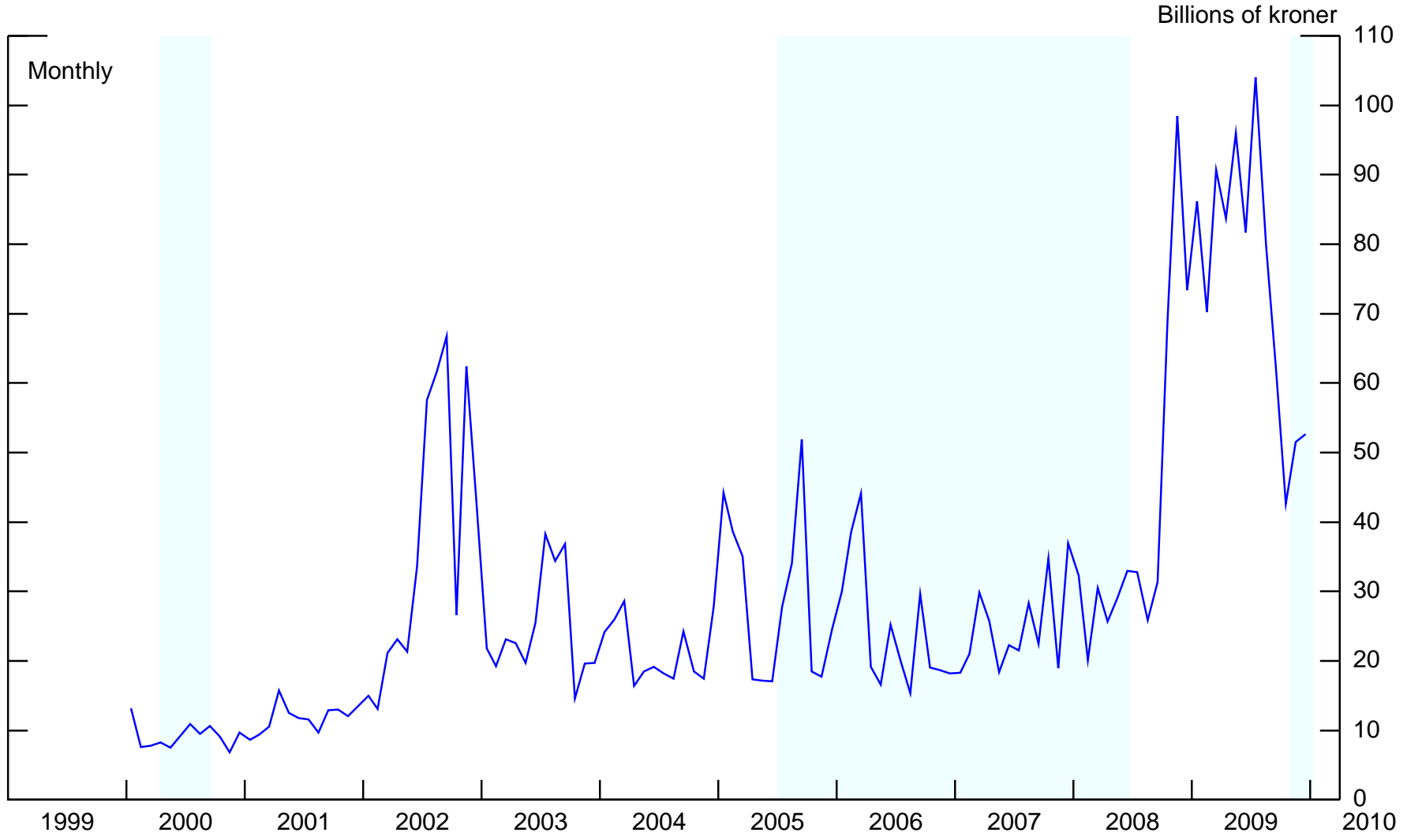


Exhibit 6b

\section{Norges Bank}

Tomorrow / Next NIBOR - Sight Deposit Rate*

Spread I

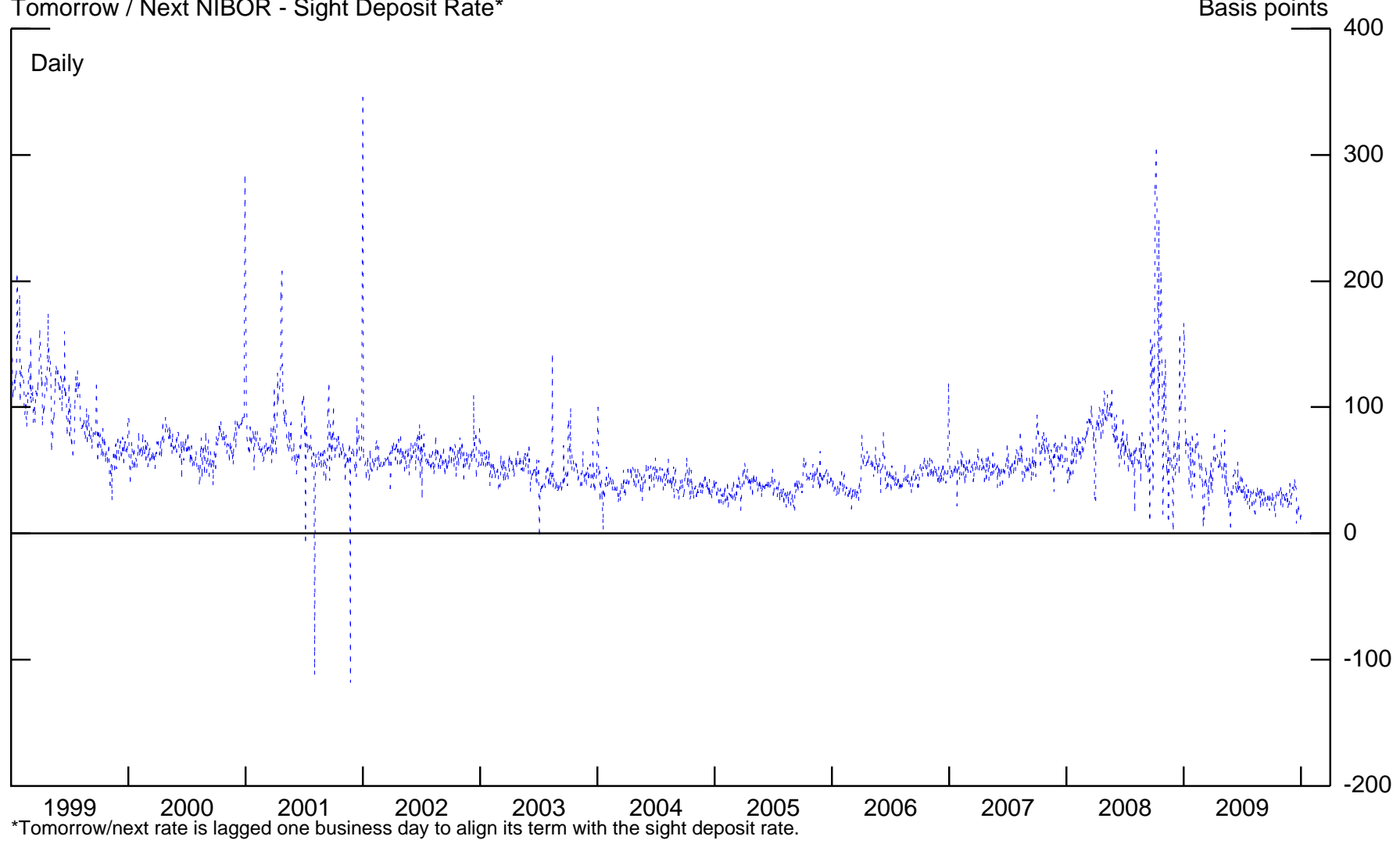

FX Swap Rate - Sight Deposit Rate

Spread II

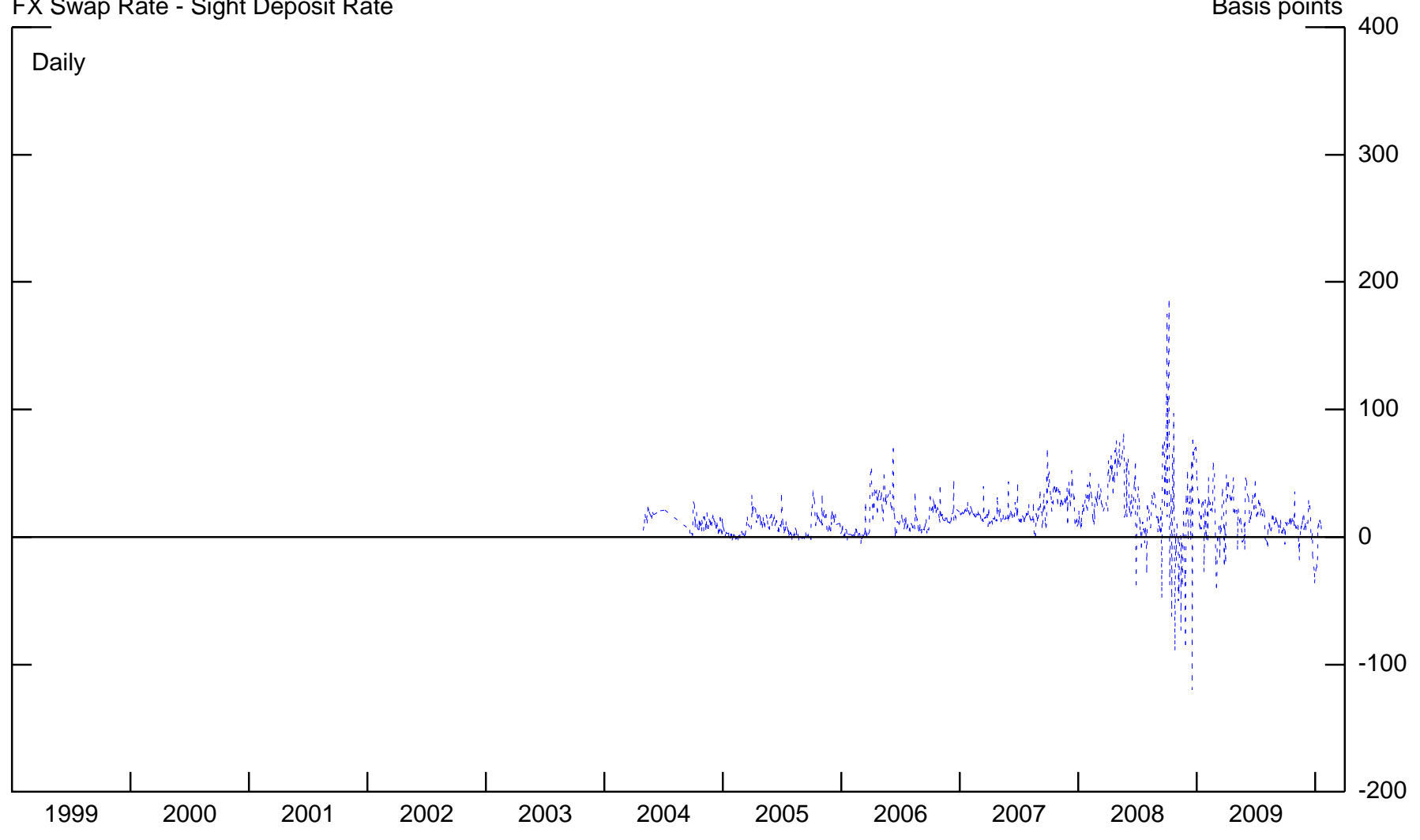


Exhibit 7a

\section{Reserve Bank of Australia}

Overnight Interest Rate

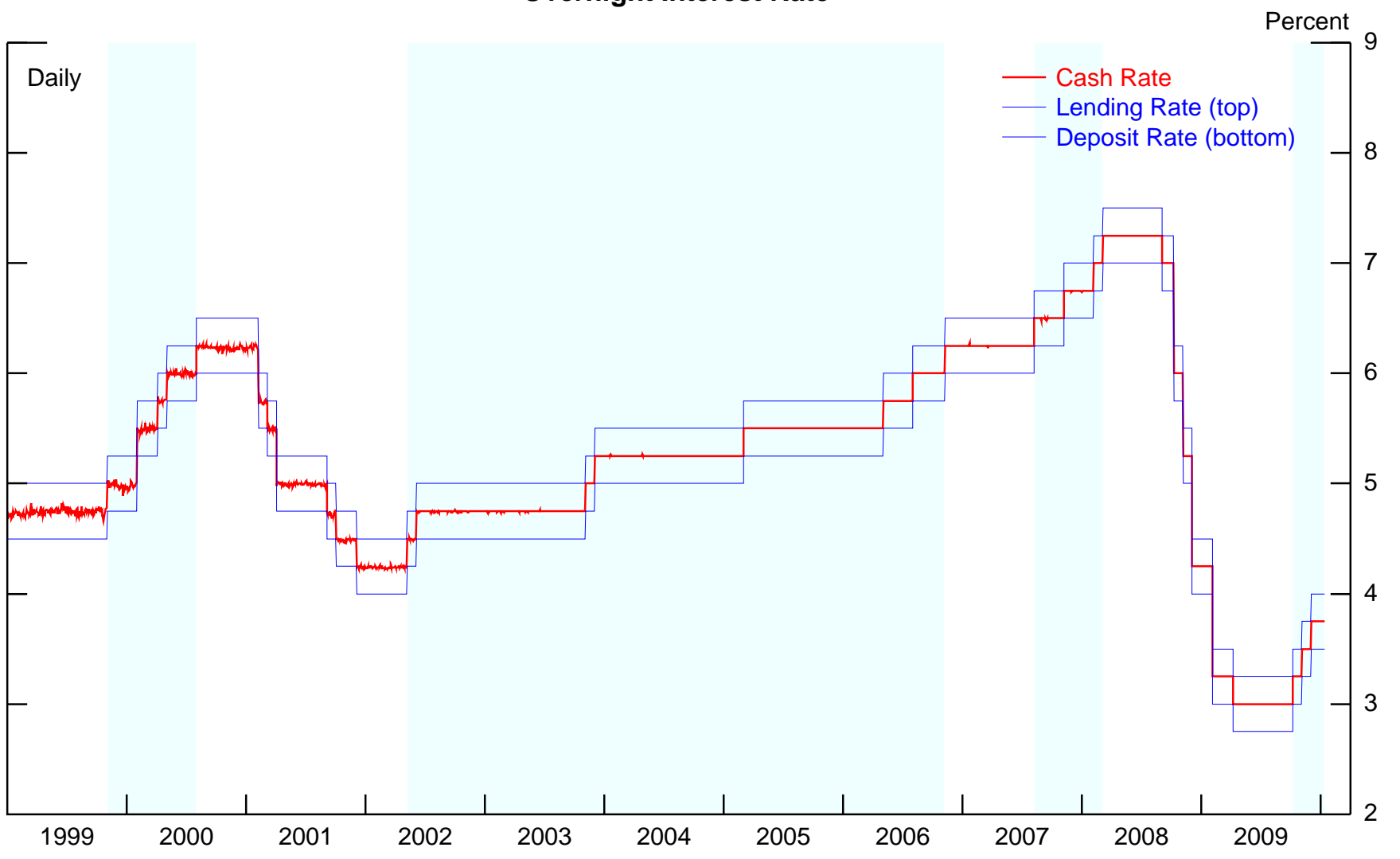

\section{Exchange Settlement Balances}

Billions of Australian dollars

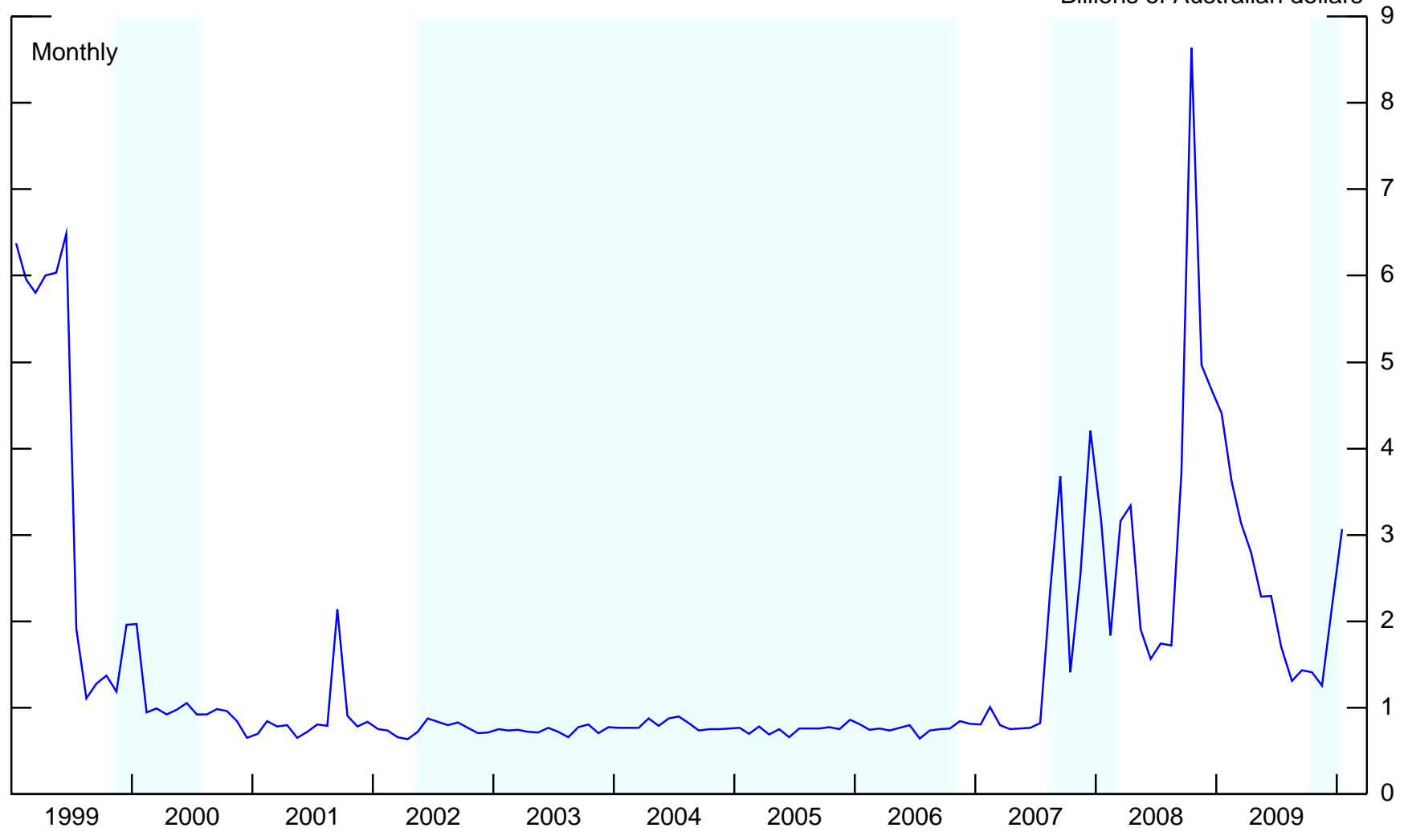


Exhibit $7 b$

\section{Reserve Bank of Australia}

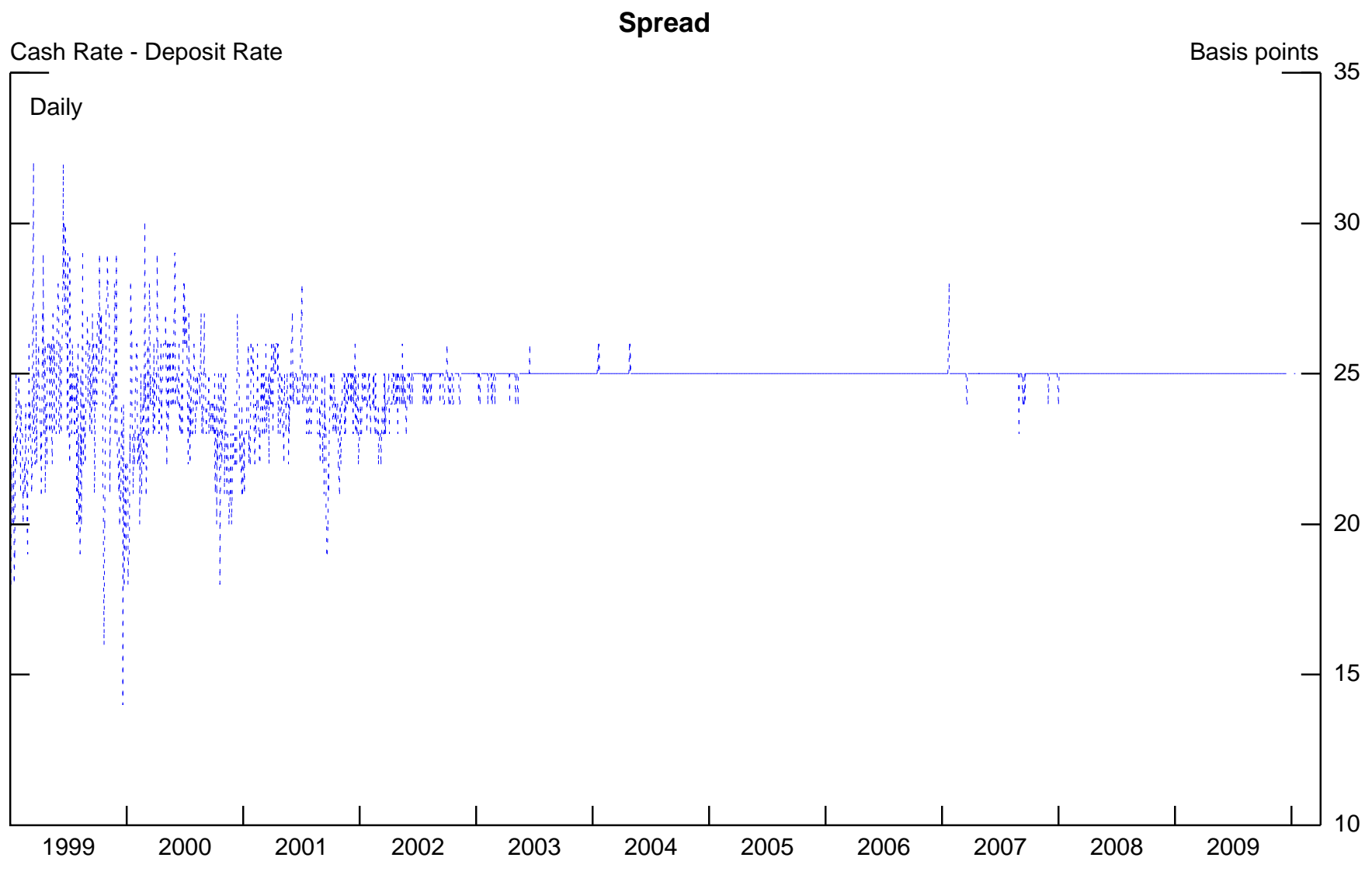




\section{Reserve Bank of New Zealand}

\section{Overnight Interest Rate}

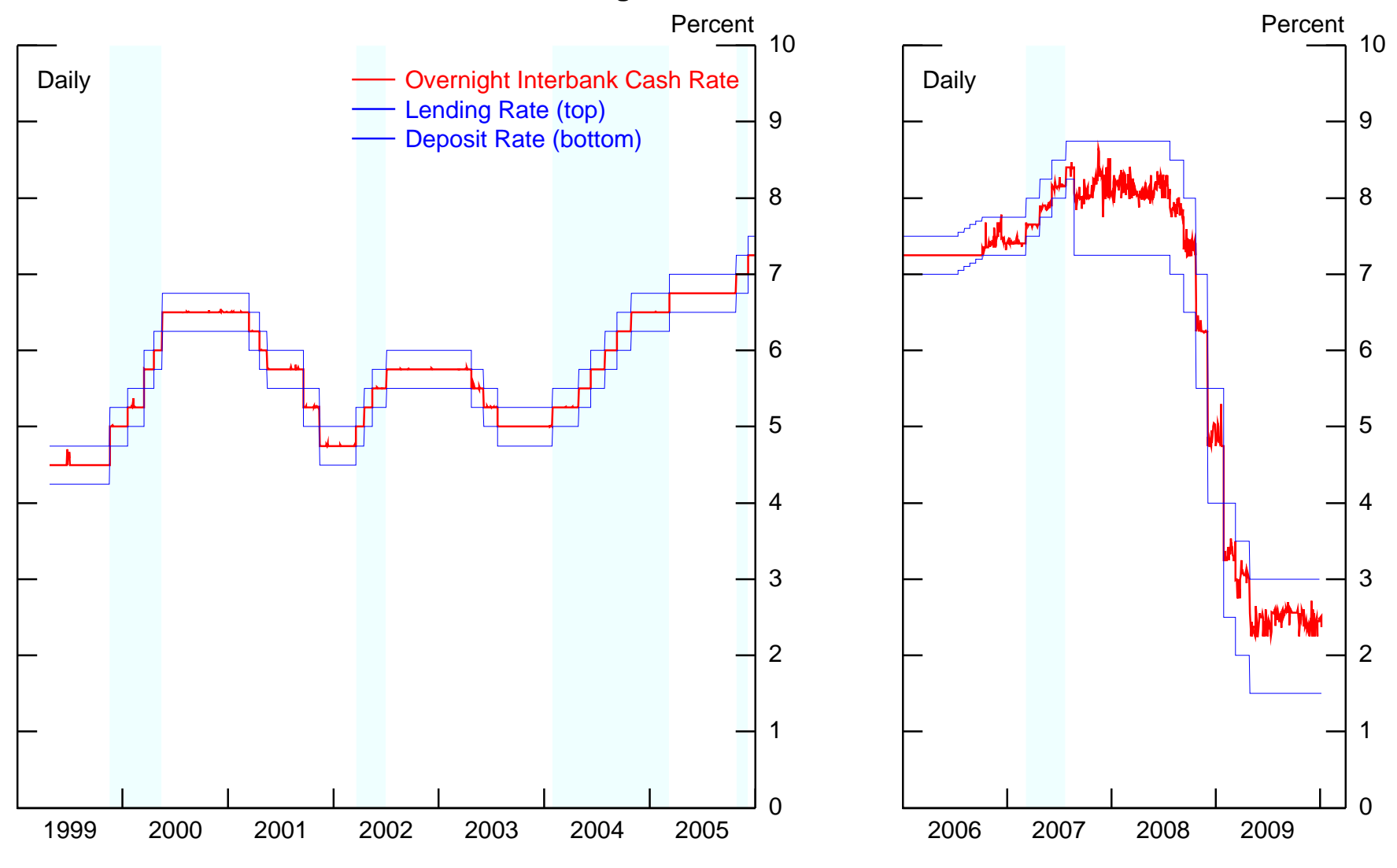

\section{Exchange Settlement Balances}
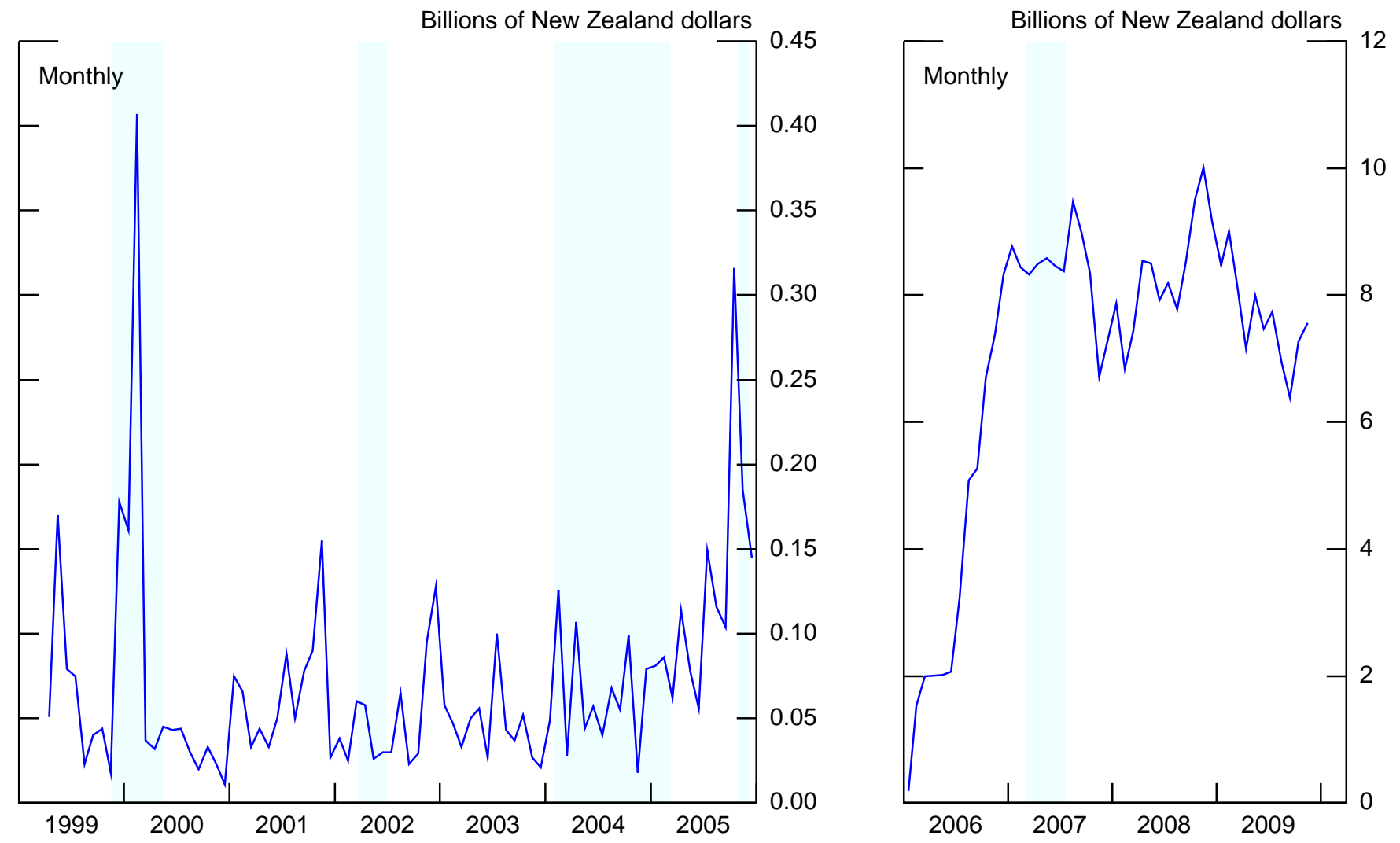
Exhibit 8b

\section{Reserve Bank of New Zealand}

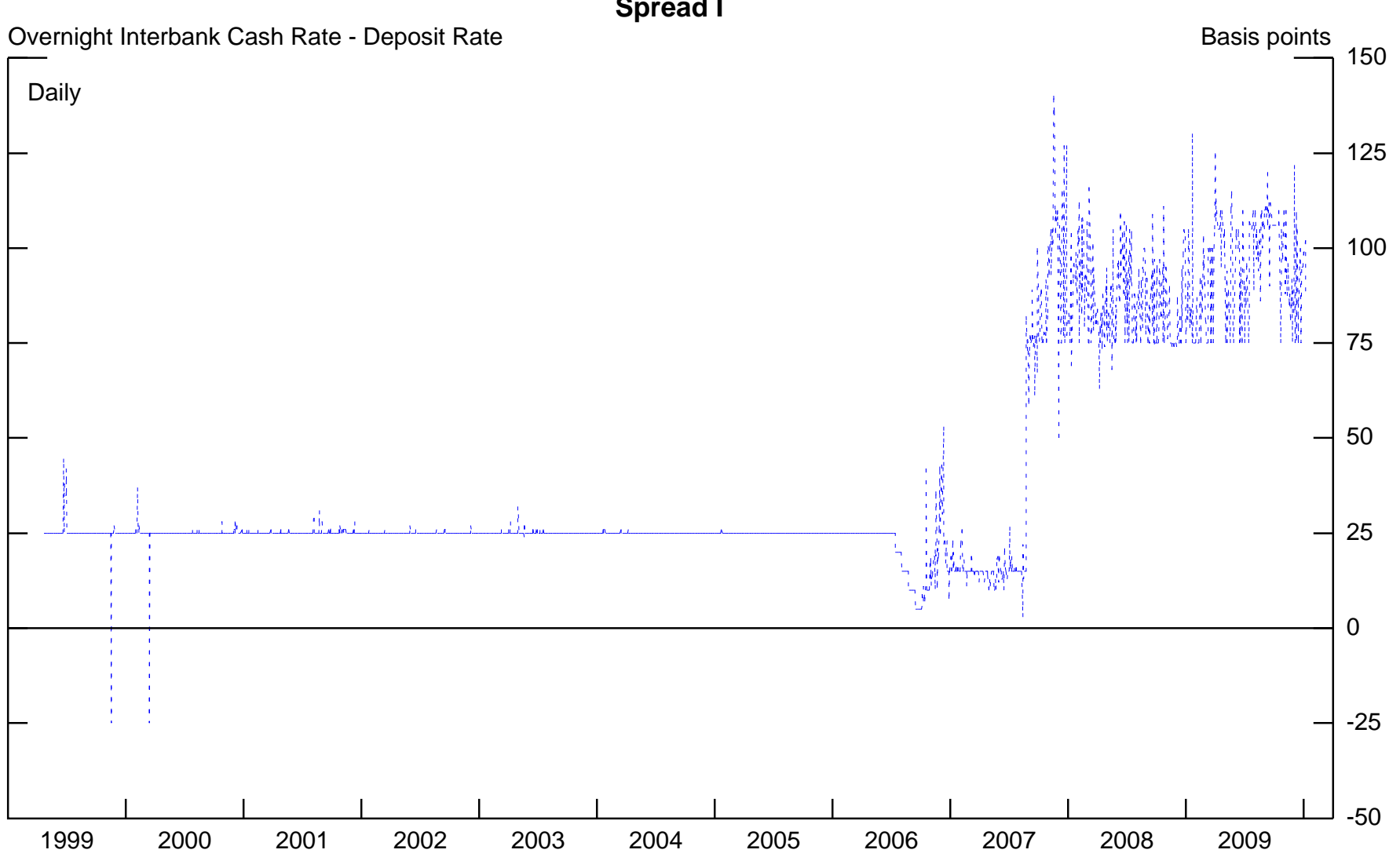

FX Swap Rate - Deposit Rate

\section{Spread II}

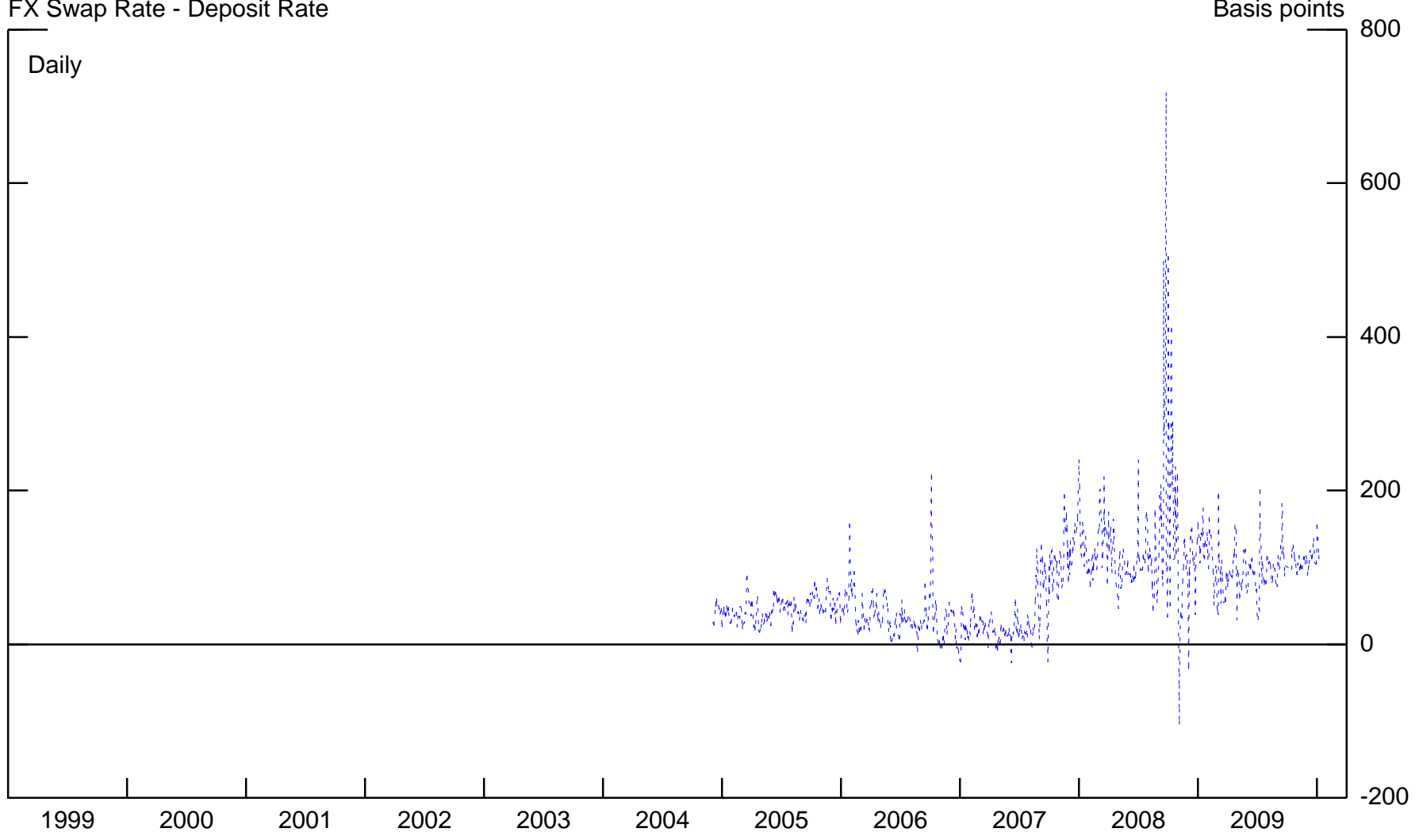


Exhibit 9a

Riksbank

Overnight Interest Rate
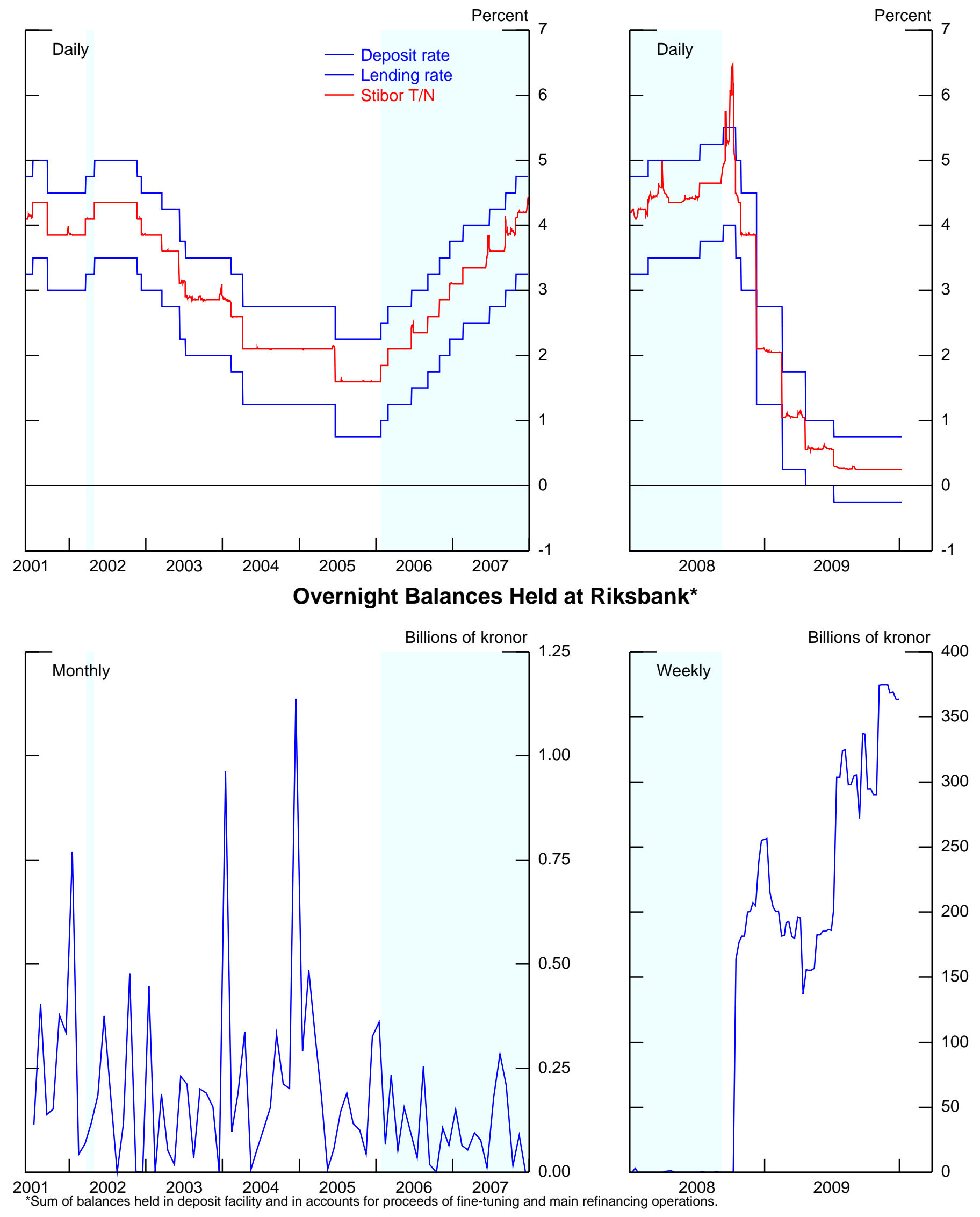
Exhibit 9b

\section{Riksbank}

Tomorrow / Next STIBOR - Deposit Facility Rate*

\section{Spread}

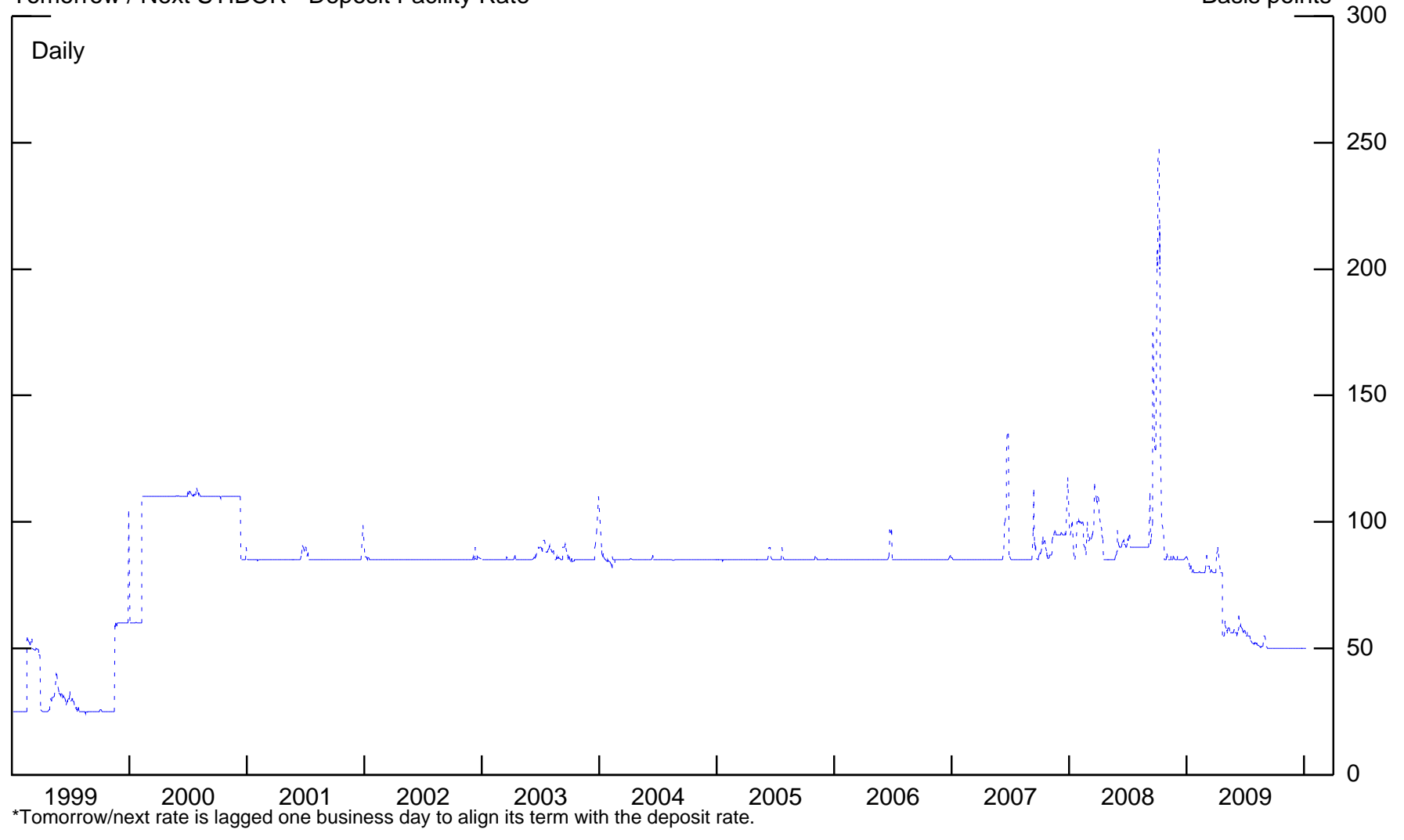


Exhibit 10
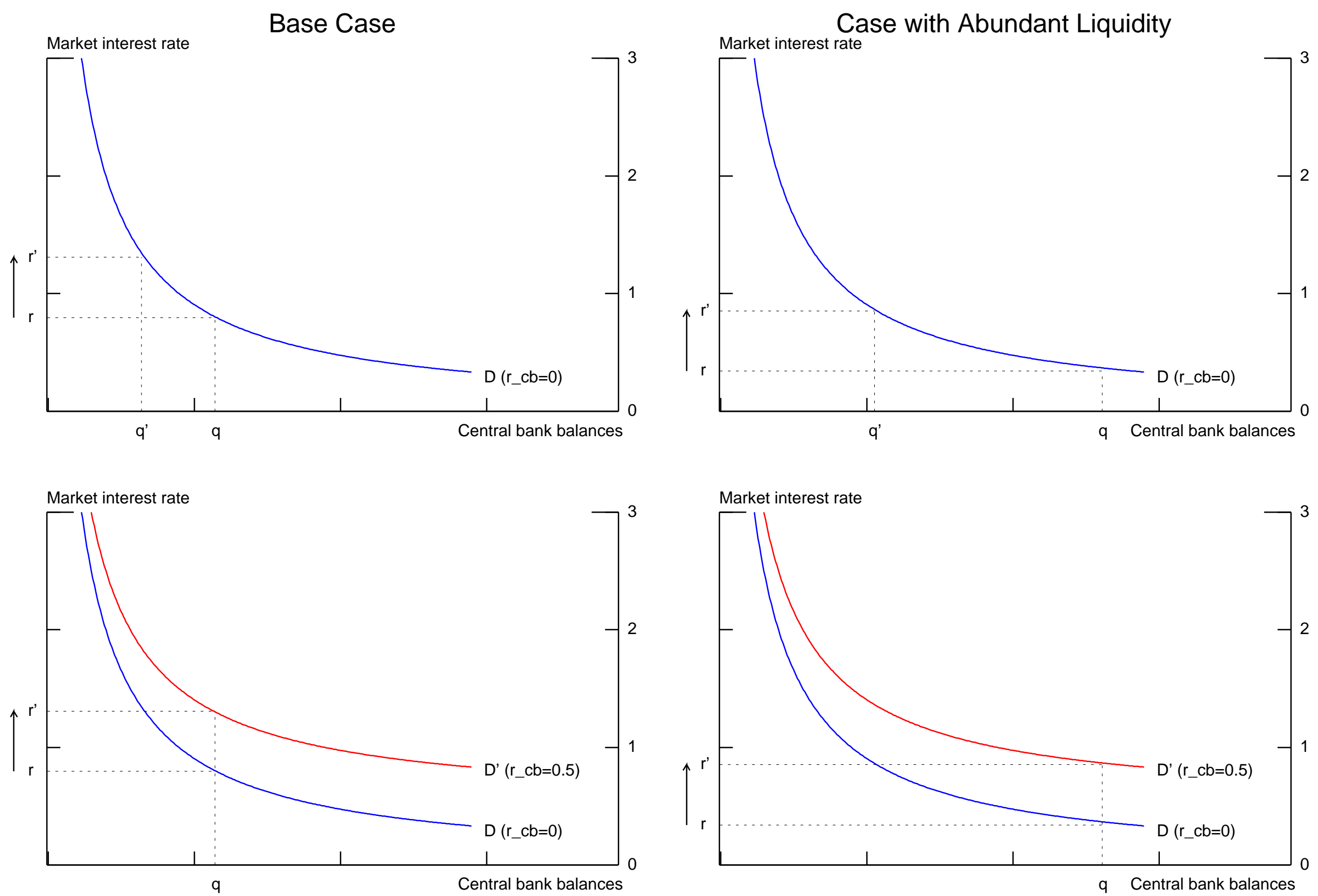

The exhibit shows the impact on the demand for reserves of a 50-basis-point increase in the target ( $r$ ) for the market rate with (bottom panels) and without (top panels) an equal increase in the rate of increase (r_cb) paid on balances held at the central bank. 